
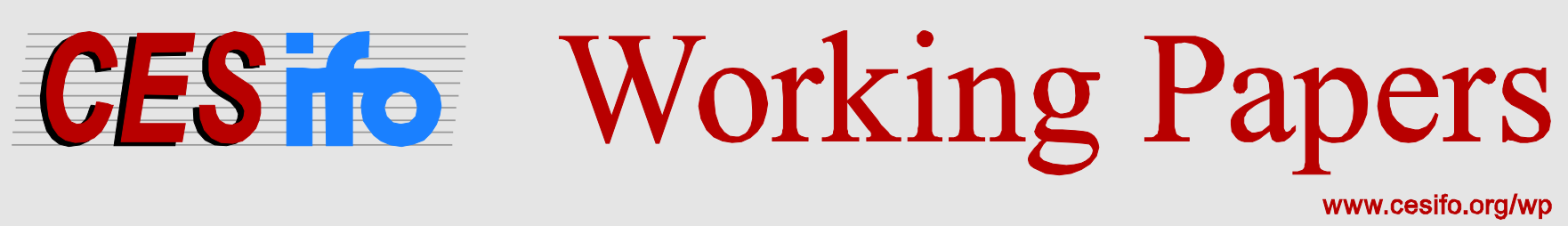

\title{
Equitable Representation in the Councils of the United Nations: Theory and Application
}

\author{
Matthew Gould \\ Matthew D. Rablen
}

CESIFO WORKING PAPER NO. 4519

CATEgory 2: Public CHOICE

DECEMBER 2013

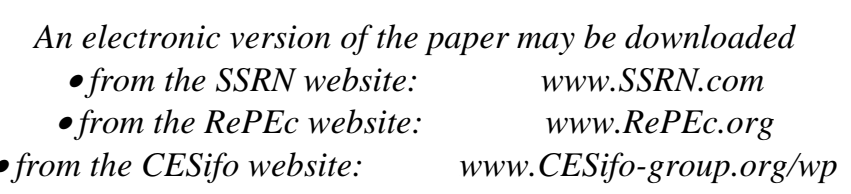




\title{
Equitable Representation in the Councils of the United Nations: Theory and Application
}

\begin{abstract}
We develop a theoretical framework for equity in council voting games (CVGs). In a CVG, a fully representative voting body delegates decision-making to a subset of the members, as describes, e.g., the United Nations Security Council (UNSC). Three equity concepts are proposed: ex-ante (procedural) equity, ex-post (outcome) equity and regional equity. The last two concepts are consistent with a new square-root rule on the probability of council membership, but no CVG can meet all three concepts. We apply our framework to evaluate the equitability of the UNSC, and the claims of those who seek to reform it.
\end{abstract}

JEL-Code: D720, D710, C710, C630.

Keywords: United Nations Security Council, United Nations, voting power, councils, squareroot rule, equity.

Matthew Gould

Department of Economics and Finance

Brunel University

UK - Uxbridge, UB8 3PH

United Kingdom

matthew.gould@brunel.ac.uk
Matthew D. Rablen

Department of Economics and Finance

Brunel University

UK - Uxbridge, UB8 $3 P H$

United Kingdom

matthew.rablen@brunel.ac.uk

November 2013

We thank the participants of the Voting Power Analysis with Reference to Institutions of Global Governance workshop at the University of Warwick for helpful comments on an early version of the paper. 


\section{Introduction}

Decision-making within international organisations is sometimes made by voting bodies that comprise a proper subset of the membership (a "council"). The pre-eminent such council, and the primary motivator of this paper, is the United Nations Security Council (UNSC), the only international body with the power to authorise the use of armed force. At any one time, the UNSC contains only 15 members from a total United Nations (UN) membership of 193. A second council operating within the UN, the United Nations Economic and Social Council (ECOSOC), contains 54 elected member countries at any one time. It is responsible for coordinating the economic, social and related work of $14 \mathrm{UN}$ specialised agencies including the World Bank and International Monetary Fund. ${ }^{1}$

In this paper we develop a theoretical framework for analysing democratic equitability in such Councils. We then apply the theory to the UNSC. The standard approach to formal quantitative appraisal of democratic equitability in international voting bodies is based upon Penrose's (1946) square-root rule. Applications include Felsenthal and Machover (1997a, 1997b, 2001, 2004, 2007), Laruelle and Widgrén (1998) and Leech (2002a) to the Council of the European Union; Napel and Widgrén (2006) to the European Parliament; Manno (1966), Newcombe, Wert and Newcombe (1971), and Dixon (1983) to the UN General Assembly (UNGA); Leech (2002b), Leech and Leech (2013), and Rapkin and Strand (2006) to the IMF Executive Board; and Leech and Leech (2005) to the World Bank Executive Boards. ${ }^{2}$ Note that these bodies are all fully representative: the UNSC stands out as the only major international body not to have been addressed by this literature. ${ }^{3}$

What lies behind this lacuna? The square-root rule is predicated on a two-stage voting model - first a national vote, second an international vote - which anticipates that all members vote in the second stage. When international decision-making is by a council, this framework

\footnotetext{
${ }^{1}$ Why do councils exist? In the case of military or emergency action, the lengthy deliberations of a fully representative body are thought to prevent such a body from being able to react with sufficient speed to developing security threats. Alternatively, councils may function in domains deemed to require detailed or specialised analysis (ECOSOC being an example). Councils can also arise at the national level. For instance, some countries have "Privy" or "Executive" Councils with the right to enact legislation during states of emergency, and/or committees that perform detailed tasks such as voting over proposed new legislation on a clause-by-clause basis prior to final approval by the parliament.

${ }^{2}$ Applications to national legislatures include Miller (2009) and Banzhaf (1968) to the U.S. Electoral College; and McLean, McMillan and Leech (2005) and Dunleavy (2010) to the UK Parliament. Again, these bodies are fully representative.

${ }^{3}$ The IMF Executive Board is composed of only 24 Executive Directors, and the World Bank Executive Board of only 25 Executive Directors. In both bodies, however, the Executive Directors represent all 188 membercountries, so each can be interpreted as fully representative.
} 
cannot be applied directly for at least two reasons. First, only a subset of members votes in the second stage. Second, this subset is not constant over time (the membership of the UNSC changes each year, for instance).

The paper contributes to both the theory and application of democratic equitability in voting bodies. In respect of theory, our first contribution is to formally define a council voting game $(\mathrm{CVG})$, to describe the Councils empirically observed in the UN. In particular, we consider a setting in which a fully representative "assembly" allocates (by election or otherwise) members to a "council". Existing measures of democratic equity with respect to fully representative bodies at time $t$ require the triple $\left(A_{t}, Q_{t}, V_{t}\right)$, where $A_{t}$ is the set of members, $Q_{t}$ is the set of member populations, and $V_{t}$ is the set of member relative voting powers. By contrast equity measures for CVGs are defined at time $t$ with respect to a 7-tuple, $C$, that nests $\left(A_{t}, Q_{t}\right)$, but in which $V_{t}$ derives from two primitives - one that determines the total relative voting power of the countries belonging to a region, and a second that divides this total between countries. In addition, $C$ also details $(i)$ the regional partition on the members of the fully representative body (the UN membership is divided into five regions) (ii) the division of council seats to regions; and (iii) the stochastic process that determines the allocation of countries to the council.

Second, we define three equity concepts for CVGs that distinguish between ex-ante and expost notions of equity, and between equity at the country and regional levels. Ex-ante equity requires that the democratic principle of one person one expected vote (OPOEV) applies among all world citizens before the allocation of countries to the council is known. Ex-ante equity, therefore, depends upon both a country's voting power when a council member, and how often they are a council member. Ex-post equity requires that, once allocation to the council is known, the democratic principle of one person one vote (OPOV) applies among the citizens of member countries of the council. It is applicable if council members are viewed as representing only their own citizens, rather than the region they belong to as a whole. Region equity requires that the total voting power of a region on the council (if its members vote independently) corresponds to that which it would obtain in a fully representative body under the OPOV principle. It is applicable if members on the council are viewed as representing their region as a whole, rather than solely their own population.

We show there is an equity rule that implements each equity concept. The ex-post equity concept is satisfied by the implementation among the members of the council of Penrose's (1946) square-root rule for voting power. Ex-ante equity also requires a square-root rule to 
hold, but on the expected voting powers before the allocation of countries to the council is known. Regional equity does not require any property of the individual voting powers, but requires that a form of aggregated square-root rule for voting power hold at the regional level. We establish an impossibility result among our notions of equity: no CVG can be both expost equitable and also region equitable. As such, a CVG that is equitable if council members only represent themselves (as opposed to their region) will necessarily fail to achieve the desired level of regional representation, and the reverse also holds.

Given that no CVG can attain all three of our equity concepts, we look for (first-best) equity rules that implement two of the three concepts. We define a CVG as country first-best if it attains both the ex-post equity and ex-ante equity concepts and as regional first-best if it attains both the ex-ante equity and regional equity concepts. We find that attainment of the country first-best requires, first, that voting power on the council satisfies Penrose's squareroot rule, and, second, that every country have an equal probability of allocation to the council. The latter condition implies that the number of council seats allocated to each region must be in proportion to the number of countries within each region. The regional first-best, however, is consistent with a range of rules. These include, as a special case, a square-root rule on the allocation probabilities (rather than on the voting powers), together with a flat rule for voting power.

With respect to application, our paper is the first we are aware of to present a quantitative assessment against formal equity concepts of the equitability of the UNSC for both individual countries and regions. As we discuss in more detail in Section 3, the UNSC is witnessing a protracted reform debate that centres on national and regional representation (see, e.g., Franck, 2003). At the regional level, reformers argue that Africa and Asia have too little power, and there is a claimed north-south divide. At the national level, countries such as Germany and Japan - who are only eligible for Non-Permanent Member (NPM) status on the UNSC - claim to be severely under-represented, and the Permanent Members (PMs) - who wield an individual veto - are argued to have too much representation.

Our analysis presents more nuanced conclusions. Our regional equity concept indeed shows that Africa, Asia and Latin America are under-represented as a whole, and that substantial north/south inequity exists. Within this picture, however, some countries in these regions actually receive too much voting power.

We do not find that the PMs receive too much voting power according to our ex-post equity 
concept - indeed these countries are in some cases substantially under-represented. We do, however, find that the combination of preferential voting power and the right to be everpresent on the UNSC makes PMs substantially over-represented in the metric of expected voting power. Japan is under-represented from both an ex-ante and ex-post perspective, but Germany is, we find, over-represented according to our ex-ante equity concept.

Our first-best concepts provide little support for the notion that the power of veto should be abolished. Both concepts are consistent with the existence of veto players, and our country first-best entails some countries receiving substantially higher voting power than do PMs under the present arrangements. We find, however, that no country is a veto player when a member of the UNSC and ever-present on the UNSC under either first-best concept. The analysis also suggests a case for allocating the right of veto to a different set of countries.

The plan of the paper is as follows: Section 2 develops a theoretical framework for the analysis of democratic equity in councils; Section 3 presents an application of the theory to the UNSC; and Section 4 concludes. All proofs are located in Appendix 1.

\section{Theory}

In this section we consider a setting in which a fully representative "assembly" allocates members to a "council". As with other aspects of the model, this setting is intended to mirror the structure observed within the UN, in which context the assembly should be interpreted as the UNGA, the main deliberative body of the UN containing all 193 of its members, and the council could refer either to the UNSC or to ECOSOC. As in the UNGA, we partition the assembly membership into regional groups. Countries are then allocated to the council in fixed proportions from each of the regions.

\subsection{Council Voting Games}

In this section we formally develop a class of voting game we term a council voting game (CVG). We begin by describing the elements of a CVG at a given time $t$.

Let the (fully-representative) assembly be denoted as the finite set $A_{t}$. We write $A_{t}=\cup_{j} R_{j t}$, where $R_{j t}$ is the $j^{\text {th }}$ region, $j \in J$. Let $R_{t}=\left\{R_{j t}\right\}_{j \in J}$ denote the set of regional partitions of $A_{t}$. Each region is a set of countries and we define $a_{i j}$ as the $i^{\text {th }}$ country within $R_{j t}$. Each country 
possesses a population denoted $q_{i j t} \in \mathbb{N}$, and let $Q_{t}=\left\{q_{i j t}\right\}_{a_{i j} \in A_{t}}$ denote the set of member populations.

The council is formed of a set of members $M_{t} \subset A_{t}$. The number of seats belonging to the members of each region $j$ is given by the vector $\mathbf{n}_{t}=\left(n_{1 t}, n_{2 t}, \ldots, n_{|J| t}\right)^{\mathrm{T}}$, where it is assumed that the number of seats for each region is always smaller than the size of the region, $\left|R_{j t}\right|>n_{j t}$. The size of the council is denoted by $N_{t} \equiv\left|M_{t}\right|=\mathbf{1} \cdot \mathbf{n}_{t}<\left|A_{t}\right|$.

Rather than specify a method of allocation of countries to the council, here we adopt a reduced form representation that allows for essentially any allocation method. An allocation process $P$ is a stochastic process that induces, at every time $t$, a probability $p_{i j t} \equiv \operatorname{Pr}\left(a_{i j} \in M_{t}\right)$ of council membership. By definition, the $p_{i j t}$ must satisfy $\sum_{a_{i j} \in R_{j}} p_{i j t}=n_{j t}$. The allocation process applying at time $t$ is denoted $P_{t}$.

We assume that each country possesses a score $s_{i j t} \geq 0$, where the set of scores is denoted as $S_{t}=\left\{s_{i j t}\right\}_{a_{i j} \in A_{i}}$. If allocated to the council, $s_{i j t}$ translates into a realised voting power, $\beta_{i j t}$, according to $\beta_{i j t}=w_{j t} s_{i j t}$, where $\sum_{a_{i j} \in M_{t}} w_{j t} s_{i j t}=1$. The $w_{j t}$ are regional weights of the form $w_{j t}=$ $w_{t}\left(\sum_{a_{i j} \in M_{t} \cap R_{j t}} s_{i j t}\right)$. Note that the $s_{i j t}$ are specified ex-ante (before $M_{t}$ is realised), but the $w_{j t}$ are not, in general determined until $M_{t}$ is realised. ${ }^{4}$ Thus, once $M_{t}$ is known, the $w_{j t}$ may be employed to choose the sum of the voting powers of the countries belonging to a given region.

We may now define a CVG in two parts:

\section{Definition 1}

(i) A council voting game at time $t$ is a tuple $C_{t}=\left(A_{t}, \mathbf{n}_{t}, R_{t}, Q_{t}, P_{t}, S_{t}, w_{t}\right)$.

(ii) A council voting game is the set $C=\left\{C_{t}\right\}_{t \in T}$.

\subsection{Equity in CVGs}

In order to derive equity concepts for a CVG at a point in time $t_{0}$ we conduct a thought experiment in which we hold constant the elements of $C$ as at time $t_{0}$, and examine the CVG formed by the resulting infinite repetition of $C_{t_{0}}$.

\footnotetext{
${ }^{4}$ In practice, once the $\beta_{i j t}$ are known, they must be induced by an appropriate decision rule - a mapping from the space of voting outcomes of the council members to an outcome space, satisfying appropriate monotonicity conditions. See, e.g., Freixas and Zwicker (2003) for a general class of $(j, k)$ decision rules.
} 
This approach may be interpreted as yielding a-priori measures of equity, for the assessment of equitability is based on the hypothetical continuation of a fixed state that is based only on information known up to time $t_{0} .{ }^{5}$ This a-priori approach implies that to determine equity concepts for $C$ at time $t_{0}$, and regardless of the actual evolution of $C$ beyond time $t_{0}$, we may consider the CVG $C^{\prime}$ described at every time $t \in T^{\prime}$ by $C_{t}^{\prime}=C_{t_{0}}$, where $T^{\prime}=1,2, \ldots$ is an infinite set. For notational emphasis, we drop all time subscripts with respect to $C_{t_{0}}$, such that $C_{t_{0}}=(A, \mathbf{n}, R, Q, P, S, w)$. Accordingly, we write $w_{t_{0}}(\cdot)=w(\cdot), q_{i j t_{0}}=q_{i j}, s_{i j t_{0}}=s_{i j}$, and so on.

With respect to $C^{\prime}$, let the expected voting power under $P$ of country $a_{i j}$ at time $t$ (before the allocation to the council is realised) be given by $\alpha_{i j t}=p_{i j t} s_{i j} \mathbf{E}_{M_{t} \in \mathcal{M}_{t}}\left(w_{j t}\right)$, where $\mathbf{E}_{M_{t} \in \mathcal{M}_{t}}\left(w_{j t}\right)$ denotes the expectation of $w_{j t}$ over $\boldsymbol{M}_{t}$, where $M_{t} \in \boldsymbol{M}_{t}$ if and only if $\left|M_{t} \cap R_{j}\right|=n_{j t}$ and $p_{i j t}>0$ for all $a_{i j} \in M_{t}$. Between the elements of two vectors $\mathbf{x}$ and $\mathbf{y}$ containing country-level statistics $x_{i j}$ and $y_{i j}$, we write $x_{i j} \propto_{M} y_{i j}$ to denote that there exists a $\lambda_{t}>0$ at every time $t$ such that $x_{i j}=\lambda_{t} y_{i j}$ for all $a_{i j} \in M_{t}$ such that $M_{t} \in \boldsymbol{M}_{t}$. We define $\propto_{R}$ and $\propto_{A}$ analogously, but where $\propto_{R}$ requires proportionality to hold for all $a_{i j} \in R_{j}$; and $\propto_{A}$ requires proportionality to hold for all $a_{i j} \in A$. Likewise, we define $\propto_{J}$, which requires proportionality to hold for all $j \in J$ between the elements of two vectors containing region-level statistics.

To focus on empirically relevant cases, we henceforth impose three further assumptions. First, as no two UN members have identical recorded populations, we assume that more than $N$ of the $q_{i j}$ are distinct. Second, we assume that $p_{i j t}=0$ for less than $|A|-N$ countries at any time $t$, to rule out degenerate cases in which the same $N$ countries are allocated to the council every time an allocation is made. Together, these assumptions are sufficient to imply that $\sum_{a_{i j} \in M_{t}} \sqrt{q_{i j}}$ is a random variable before $M_{t}$ is realised. Third, we assume that $p_{i j t} \neq 0$ on a nonempty subset of $T^{\prime}$ for every $a_{i j} \in A$. This assumption rules out the existence of countries that can never be allocated to the council, hence $s_{i j} \propto_{M} \beta_{i j t}$ implies $s_{i j} \propto_{A} \beta_{i j t}$.

\subsubsection{Equity concepts}

We base our concepts of democratic equity upon an idealised three-stage decision-making process. In Stage 1, a national ballot is held in each country $a_{i j} \in A$ under a simple majority decision rule. In Stage 2 a subset $M_{t} \subset A$ of countries are allocated to the council. In Stage 3, countries $a_{i j} \in M_{t}$ cast their vote according to the outcome of their national ballot in Stage 1 .

\footnotetext{
${ }^{5}$ The alternative a-posteriori approach is instead backwards looking, using historical data to estimate realised equitability over a period of time.
} 
We develop three distinct equity concepts. Our first notion of equity we term ex-ante equity (AE). According to AE, it is desirable that the expected voting power of every world citizen is equal before the allocation of countries to the council is made in Stage 2, i.e., OPOEV. The ex-ante perspective acknowledges that the power of a world citizen in the council depends not only on the voting power of his or her country when it is a member of the council, but also on how frequently his or her country is a member of the council.

We develop two alternative concepts of ex-post equity. The first, which we term simply expost equity $(\mathrm{PE})$, is that it is desirable that the democratic principle of OPOV hold among the citizens of council member countries, once these are known. This concept is of particular relevance if council members are viewed as representing their own populations, rather than their region at large.

Our final concept of equity, regional equity (RE), is also ex-post in nature. According to RE, it is desirable that the combined voting power of the council members from each region be proportionate with the level of representation that each region would obtain in a fully representative voting body satisfying OPOV. This concept is of particular relevance if council members are viewed as representing their region, rather than only themselves, for it entails that voting power be commensurate with the population of the region a country belongs to (rather than with its own country-specific population). ${ }^{6}$

The distinction between our ex-ante and ex-post concepts of equity is analogous to the distinction made by scholars of law between "procedural" and "distributive" justice (e.g., Konovsky, 2000); and by scholars of psychology between "procedural" and "outcome" fairness (e.g., De Cremer et al., 2010). The AE concept requires procedural equitability, but not outcome equitability, whereas $\mathrm{PE}$ and RE require outcome equitability, but not procedural equitability.

All three equity concepts need not apply to every council, or in equal degrees. In some contexts, country concerns may prevail over regional, while the opposite could apply in other contexts. The applicability of RE relative to PE, for instance, depends largely on whether countries are viewed as representing only themselves, or the whole of the region to which they belong, when a member of the council. In the case of the UNSC, we appear to observe

\footnotetext{
${ }^{6}$ The logical ex-ante counterpart to RE is that the combined expected voting power of the council members from each region be proportional to the level of representation that each region would obtain in a fully representative voting body satisfying OPOV. We do not consider this equity concept separately, however, for if a CVG satisfies AE at time $t$, then the ex-ante counterpart to RE is necessarily satisfied too. See footnote 11 for further details.
} 
evidence of a concern for each equity notion. As we detail later, both country- and regionallevel equity concepts are frequently cited by those that propose reform. In respect of ex-ante equity, it is notable that several of the proposals for reform of the UNSC detailed in Cox (2009) leave the country voting powers unchanged, but modify the allocation probabilities, suggesting that world leaders understand (at least intuitively) the importance of allocation probability as well as voting rights. ${ }^{7}$

To help formalise each of these equity concepts we make the following assumption on voting in Stage 1:

Assumption 1 Voting in Stage 1 is assumed, a-priori, to be independent within and across countries.

As argued by, e.g., Felsenthal and Machover (1997c, 2003), Assumption 1 should be understood as reflecting Bernoulli's Principle of Insufficient Reason: a-priori we do not know how countries will actually vote. An alternative a-priori assumption might be that voting is perfectly correlated within regions, but independent across regions, such that the regions act as unitary blocs. We note, however, that if regions become unitary players the council becomes a fully-representative body that may be analysed with existing theory. In this sense, the analysis of equity in CVGs differs from that in fully representative bodies only if individual countries are a-priori distinct from regions. ${ }^{8}$

Proposition 1 Under Assumption 1:

(i) a CVG is AE at time $t_{0}$ if and only if $C^{\prime}$ satisfies $\alpha_{i j t} \propto_{A} \sqrt{q_{i j}}$;

(ii) a CVG is PE at time $t_{0}$ if and only if $C^{\prime}$ satisfies $\beta_{i j t} \propto_{M} \sqrt{q_{i j}}$;

(iii) a CVG is RE at time to if and only if $C^{\prime}$ satisfies $\sum_{a_{i j} \in M_{t} \cap R_{j}} \beta_{i j t} \propto_{J} \sum_{a_{i j} \in R_{j}} \sqrt{q_{i j}}$.

In interpreting Proposition 1, it is most straightforward to begin with part (ii), which restates the inspiration of Penrose (1946) that, under Assumption 1, OPOV is achieved by a decision rule that sets voting power in the council to be in proportion to the square-root of each

\footnotetext{
${ }^{7}$ Examples include proposals that allow some current NPMs to be ever-present members, proposals that would extend the term length of some NPM seats, and proposals that would introduce seats that are allocated on a strict rotation basis within regions.

${ }^{8}$ Empirically, countries on the UNSC do seem to act as distinct entities within regions. Each council member has full sovereignty over how it votes and countries pour large sums of money into campaigns for election to the UNSC (see, e.g., Malone, 2000), suggesting that they do not perceive membership by another of their regional group to be a perfect substitute for their own membership. Also, the voting behaviour in the UNGA of serving members of the UNSC is no more similar to that of their regional members than to the votes of the remaining UNGA members (Lai and Lefler, 2009).
} 
country's population. ${ }^{9}$ Part (i) may then be understood as simply requiring the same squareroot rule to hold, but this time on the expected voting powers (before the allocation to the council in Stage 2 is known).

For part (iii), note that, under Assumption 1, it holds that the voting power of a region is the sum of the voting powers of the individual members. ${ }^{10}$ Hence, via Penrose's square-root rule, a region's voting power in a fully representative body satisfying OPOV is proportional to $\sum_{a_{i j} \in R_{j}} \sqrt{q_{i j}} \cdot 11$

\subsection{Equity Rules}

What restrictions are required on the underlying parameters to implement the conditions in Proposition 1 ? To assist in the analysis of this and later questions we first define some special cases in which either the $s_{i j}, \beta_{i j t}$ or $p_{i j t}$ are invariant on some dimensions:

\section{Definition 2}

(i) (regional s-invariance) $C^{\prime}$ satisfies regional s-invariance if and only if $s_{i j}=s_{i^{\prime} j}=s_{j}$ for all $a_{i j}, a_{i^{\prime}} \in R_{j}$ and for all $j \in J$;

(ii) ( $\beta$-invariance) $C^{\prime}$ satisfies $\beta$-invariance if and only if $\beta_{i j t}=\beta_{i j^{\prime} t}=\beta_{i j t^{\prime}}=\beta$ for all $a_{i j}, a_{i^{\prime} j^{\prime}} \in$ $A$ and for all $t, t^{\prime} \in T^{\prime}$;

(iii) $\left(p_{t}\right.$-invariance) $C^{\prime}$ satisfies $p_{t}$-invariance if and only if $p_{i j t}=p_{i j t^{\prime}}=p_{i j}$ for all $a_{i j} \in A$ and for all $t, t^{\prime} \in T^{\prime}$;

(iv) (regional p-invariance) $C^{\prime}$ satisfies regional $p$-invariance if and only if $p_{i j t}=p_{i j t^{\prime}}=p_{i^{\prime} j t}=$ $p_{j}$ for all $a_{i j}, a_{i^{\prime} j} \in R_{j}$, for all $t, t^{\prime} \in T$ and for all $j \in J$;

(v) (p-invariance) $C^{\prime}$ satisfies $p$-invariance if and only if $p_{i j t}=p_{i j t^{\prime}}=p_{i^{\prime} j^{\prime} t}=p$ for all $t, t^{\prime} \in T^{\prime}$ and for all $a_{i j}, a_{i^{\prime} j^{\prime}} \in A$.

It is straightforward to observe that $p$-invariance and regional $p$-invariance both imply $p_{t}$ invariance, and that $p$-invariance implies regional $p$-invariance. Less obvious is that $\beta$ invariance implies regional $s$-invariance. As the weights $w_{j t}$ are region specific, they cannot

\footnotetext{
${ }^{9}$ For equity rules under alternatives to Assumption 1 see Kirsch and Langner (2011).

${ }^{10}$ If Assumption 1 were replaced with the assumption that voting is correlated across countries within a region, but independent across regions, then a different concept would be required as regions would vote as blocs on the council and, in general, the voting power of a bloc does not equal the sum of the individual voting powers of the members when voting independently.

${ }^{11}$ Following on from footnote 6 , if the condition for $\operatorname{AE}\left(\alpha_{i j t} \propto_{A} \sqrt{q_{i j}}\right)$ is summed over $a_{i j} \in R_{j}$ on both sides, then one obtains the natural statement of the ex-ante counterpart to RE.
} 
be used to adjust the $s_{i j}$ of an individual country. Hence, $\beta$-invariance is implemented if and only if regional $s$-invariance holds and $w\left(z_{j t}\right)=n_{j}\left(N z_{j t}\right)^{-1}$.

We now state our implementation rules:

Proposition 2 Under Assumption 1:

(i) $\quad C$ is $A E$ at time $t_{0}$ if and only if $C^{\prime}$ satisfies (a) $p_{t}$-invariance; and (b) $p_{i j}^{\mathrm{AE}} s_{i j}^{\mathrm{AE}} \propto_{R} \sqrt{q_{i j}}$;

(ii) C is PE at time $t_{0}$ if and only if $C^{\prime}$ satisfies $(a) w\left(z_{j t}\right)=\frac{1}{\sum_{j \in J} z_{j t}}$; and $(b) s_{i j}^{\mathrm{PE}} \propto_{A} \sqrt{q_{i j}}$;

(iii) $C$ is $R E$ at time $t_{0}$ if and only if $C^{\prime}$ satisfies $w\left(z_{j t}\right)=\left(\frac{\sum_{A_{i j} \in R_{j}} \sqrt{q_{i j}}}{\sum_{A_{i j} \in A} \sqrt{q_{i j}}}\right) \frac{1}{z_{j t}}$.

Part $(i)$ of Proposition 2 establishes a rule for AE. Intuitively, it states that, under $p_{t^{-}}$ invariance, any choice of the $s_{i j}$ and $p_{i j}$ such that $p_{i j}^{\mathrm{AE}} s_{i j}^{\mathrm{AE}} \propto_{R} \sqrt{q_{i j}}$ holds within region is implied by $\mathrm{AE}$, and implies $\mathrm{AE}$ for an appropriate choice of $w(\cdot)$. This result is consistent with a range of rules for the underlying $s_{i j}$ and $p_{i j}$, including a flat rule for the $p_{i j}$ together with a squareroot rule for the $s_{i j}$, and vice-versa. Part (ii) of Proposition 2 establishes an equity rule that implements PE. Condition ( $a$ ) requires that $w_{j t} \propto_{A}\left(\sum_{a_{i j} \in M_{t}} s_{i j}\right)^{-1}$, for this choice of $w(\cdot)$ implies that, at each time $t$, the $\beta_{i j t}$ are obtained by simply normalising the $s_{i j}$ of the council members, such that $s_{i j}^{\mathrm{PE}} \propto_{A} \beta_{i j t}$. Condition $(b)$ then ensures Penrose's square-root rule by asking the $s_{i j}^{\mathrm{PE}}$ to satisfy a square-root rule. As PE does not require procedural equity, however, it imposes no requirements on the $p_{i j t}$.

Part (iii) establishes an equity rule that implements RE. As RE imposes a requirement upon the sum of the voting powers of the council members from each region, a restriction must be placed on the regional weights in order to guarantee that $\sum_{a_{i j} \in M_{t} \cap R_{j}} \beta_{i j t} \propto_{J} \sum_{a_{i j} \in R_{j}} \sqrt{q_{i j}}$. Note, however, that RE imposes nothing upon the distribution of voting power within each region, so no restriction upon the $s_{i j}$ is made.

Although we show in the next section that $\mathrm{AE}$ is compatible with both $\mathrm{PE}$ and $\mathrm{RE}$, we find that no CVG can be both PE and RE:

Proposition 3 Under Assumption 1 no $C$ is both PE and RE at time $t_{0}$. 
The proof of Proposition 3 shows that for both PE and RE to hold, then $\sum_{a_{i j} \in M_{i} \cap R_{j}} \sqrt{q_{i j}}$ must be non-random. The most general way this could occur is if the $q_{i j}$ satisfied the following property:

Definition 3 ( $q$ sub-regional invariance $-q S R I) C^{\prime}$ satisfies $q S R I$ if and only if $q_{i j}=q_{i^{\prime} j}$ for all $a_{i^{\prime} j}, a_{i j} \in r_{k_{j} j}$, where the $r_{k_{j}}$ partition $R_{j}$ for each $j$, and $k_{j}=1, \ldots, g_{j}$, where $g_{j}$ is an integer belonging to $\left[1, n_{j}\right]$.

If $n_{k_{j} j}$ seats are allocated to each sub-region $r_{k_{j} j}$, where $\sum_{a_{i j} \in r_{k j}} n_{k_{j} j}=n_{j}$, then under $q$ SRI we have that $\sum_{a_{i j} \in M_{t} \cap R_{j}} \sqrt{q_{i j}}=\sum_{k_{j} \in g_{j}} n_{k_{j} j} \sqrt{q_{i j}}$, which is non-random. But we rule out $q$ SRI by assumption in Section 2.2 (as, empirically, it is wholly implausible), from which the Proposition follows. Accordingly, in a world where country populations are distinct, it is necessary for world leaders to accept that a CVG that achieves PE will necessarily entail some degree of regional inequity, and that the reverse also holds.

\subsubsection{The first-best}

Proposition 3 implies that no equity rule can achieve all three concepts we consider. It is possible, however, to derive equity rules that achieve two of the three concepts. The rule that achieves both $\mathrm{AE}$ and $\mathrm{PE}$ we term the country first-best (CFB), and the rule that achieves both $\mathrm{AE}$ and $\mathrm{RE}$ we term the regional first-best (RFB).

We first prove a helpful Lemma:

Lemma 1 If a CVG satisfies $p_{i j t} \propto_{A} f_{i j t}$, then $n_{j} \propto_{J} \sum_{a_{i j} \in R_{j}} f_{i j t}$.

Lemma 1 follows from the observation that the allocation probabilities must, by definition, satisfy $\sum_{a_{i j} \in R_{j}} p_{i j t}=n_{j}$, hence $n_{j}=\sum_{a_{i j} \in R_{j}} p_{i j t} \propto_{J} \sum_{a_{i j} \in R_{j}} f_{i j t}{ }^{12}$

Proposition 4 Under Assumption 1:

(i) (Country first-best) $C$ is $A E$ and $P E$ at time $t_{0}$ if and only if $C^{\prime}$ satisfies (a) $w\left(z_{j t}\right)=\frac{1}{\sum_{j \in J} z_{j t}} ;(b)$ p-invariance - hence $n_{j}^{\mathrm{CFB}} \propto_{J}\left|R_{j}\right|$; and (c) $s_{i j}^{\mathrm{CFB}} \propto_{A} \sqrt{q_{i j}}$.

\footnotetext{
${ }^{12}$ As the $n_{j}$ are integers, this proportionality condition cannot hold exactly unless $\left(N \sum_{a_{i j} \in R_{j}} f_{i j t}\right)\left(\sum_{j \in J} \sum_{a_{i j} \in R_{j}} f_{i j t}\right)^{-1}$ is an integer for every $j$. We therefore interpret the condition $n_{j} \propto_{J} \sum_{a_{i j} \in R_{j}} f_{i j t}$ to imply that, for given $f_{i j t}$, the $n_{j}$ are set to achieve maximal proximity to exact proportionality (under an appropriate metric).
} 
(ii) (Regional first-best) $C$ is $A E$ and $R E$ at time $t_{0}$ if and only if $C^{\prime}$ satisfies (a)

$$
w\left(z_{j t}\right)=\left(\frac{\sum_{A_{i j} \in R_{j}} \sqrt{q_{i j}}}{\sum_{A_{i j} \in A} \sqrt{q_{i j}}}\right) \frac{1}{z_{j t}} ; \text { and }(b) p_{i j t}^{\mathrm{RFB}} s_{i j}^{\mathrm{RFB}} \mathbf{E}_{M_{t} \in \mathcal{M}_{t}}\left(\frac{1}{\sum_{A_{i j} \in M_{t} \cap R_{j}} s_{i j}^{\mathrm{RFB}}}\right) \propto_{A} \frac{\sqrt{q_{i j}}}{\sum_{A_{i j} \in R_{j}} \sqrt{q_{i j}}} .
$$

According to Proposition 4, the country first-best is achieved by the combination of Penrose's square-root rule for voting power (which is implied by conditions $a$ and $c$ ) together with a flat rule for allocation probability. The proof is a straightforward consequence of parts $(i)$ and (ii) of Proposition 2. The result illustrates that, although the AE and PE concepts are compatible, potential tensions exist between them. On the one hand, there is no inherent conflict if all countries share the same allocation probability. On the other hand, if the major world powers desire to be members of bodies such as the UNSC and ECOSOC on a more regular basis than are lesser powers, then unequal allocation probabilities are required. With unequal allocation probabilities, AE implies that a country with a low allocation probability must be compensated for longer expected spells outside the council by the exercise of greater voting power when a member of the council. In this case, AE is in conflict with PE, for it results in systematic deviations from Penrose's square-root rule.

Part (ii) of the Proposition, which is a straightforward consequence of parts (i) and (iii) of Proposition 2, establishes the conditions needed for AE and RE. The Proposition clarifies that $p_{i j}^{\mathrm{AE}} s_{i j}^{\mathrm{AE}} \propto_{R} \sqrt{q_{i j}}$ is a necessary condition for RFB, but it is not sufficient, for (unlike under $\mathrm{AE}$ alone) we can now no longer choose $w(\cdot)$ arbitrarily. As there remains a degree of flexibility over the choice of the underlying $s_{i j}$ and $p_{i j t}$ that satisfy RFB, in the following corollary we highlight some special cases.

Corollary 1 If $C$ satisfies $A E$ and $R E$ at time $t_{0}$ then:

(i) If $C^{\prime}$ satisfies regional s-invariance then it also satisfies (a) $w\left(s_{j}^{R F B}\right)=\frac{1}{n_{j} s_{j}^{R F B}}\left(\frac{\sum_{A_{i j} \in R_{j}} \sqrt{q_{i j}}}{\sum_{A_{i j} \in A} \sqrt{q_{i j}}}\right) ;(b) p_{t}$-invariance; and $(c) p_{i j}^{\mathrm{RFB}} \propto_{A} n_{j}\left(\frac{\sqrt{q_{i j}}}{\sum_{A_{i j} \in R_{j}} \sqrt{q_{i j}}}\right) \propto_{R} \sqrt{q_{i j}} ;$

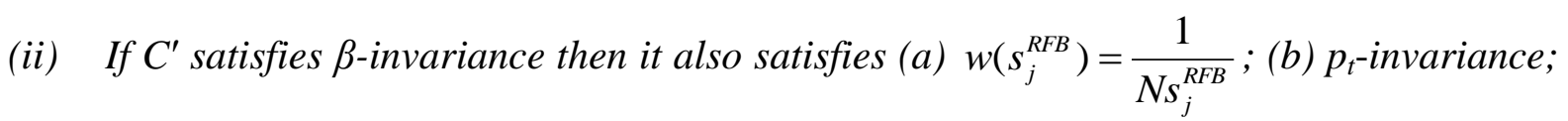
and (c) $p_{i j}^{\mathrm{RFB}} \propto_{A} \sqrt{q_{i j}}$.

(iii) If $C^{\prime}$ satisfies regional p-invariance then it also satisfies 


$$
s_{i j}^{\mathrm{RFB}}\left(\sum_{0 \leq h_{1}<\cdots<h_{n_{j}} \leq R_{j} \mid} \frac{1}{\sum_{k=1}^{n_{j}} s_{h_{k} j}^{\mathrm{RFB}}}\right) \propto_{A} \frac{1}{p_{j}^{\mathrm{RFB}}}\left(\frac{\left|R_{j}\right| !}{n_{j} !\left(\left|R_{j}\right|-n_{j}\right) !}\right)\left(\frac{\sqrt{q_{i j}}}{\sum_{A_{i j} \in R_{j}} \sqrt{q_{i j}}}\right) \propto_{R} \sqrt{q_{i j}} ;
$$

(iv) If $C^{\prime}$ satisfies p-invariance then it also satisfies

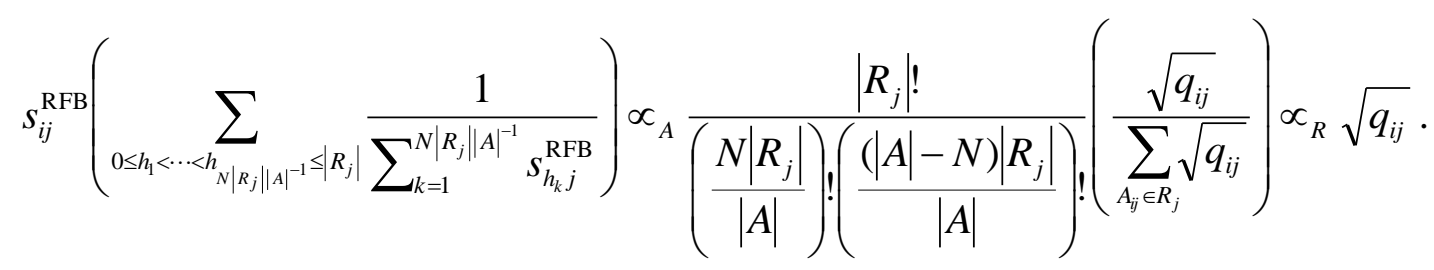

If the $s_{i j}$ in part (ii) of Proposition 4 are restricted to satisfy regional $s$-invariance then we have $\sum_{a_{i j} \in M_{i} \cap R_{j}} s_{i j}^{\mathrm{RFB}}=n_{j} s_{j}^{\mathrm{RFB}}$. As this is non-random, $\sum_{a_{i j} \in M_{i} \cap R_{j}} s_{i j}^{\mathrm{RFB}}$ may be removed from the expectation in condition $(b)$ of part ( $i i)$ of Proposition 4 to give part ( $i$ ) of Corollary 1. Part (ii) uses Lemma 1 to additionally impose $n_{j}^{\mathrm{RFB}}=N\left(\sum_{a_{i j} \in R_{j}} \sqrt{q_{i j}}\right)\left(\sum_{a_{i j} \in A} \sqrt{q_{i j}}\right)^{-1}$. According to part $(i)$, therefore, RFB is consistent with a flat rule for voting power together with a squareroot rule for allocation probability (where both rules hold within, but not across, regions). Part (ii) clarifies, that, if the division of seats to regions is made proportional to $\sum_{a_{i j} \in R_{j}} \sqrt{q_{i j}}$, then RFB is consistent with a flat rule for voting power together with a square-root rule for allocation probability (where both rules hold within and across regions). Thus, the RFB concept is consistent with a square-root rule that - unlike Penrose's - holds on the allocation probabilities rather than the voting powers.

Part (iii) of the Corollary considers the RFB concept when the allocation probabilities satisfy a flat rule within regions. Under this assumption, the $s_{i j}$ follow a complex rule that relates to (but does not correspond to) a within-region square-root rule. Part (iv) is obtained by further setting $n_{j}^{\mathrm{RFB}}=N\left|R_{j} \| A\right|^{-1}$ in part (iii). ${ }^{13}$ Despite their apparently complex forms, these two rules for $s_{i j}$ have a straightforward intuition. Suppose that we assert the approximation $\mathbf{E}_{M_{t} \in \mathcal{M}_{t}}$ $\left(\left(\sum_{a_{i j} \in M_{t} \cap R_{j}} s_{i j}\right)^{-1}\right) \approx\left(\mathbf{E}_{M_{t} \in \mathcal{M}_{t}}\left(\sum_{a_{i j} \in M_{t} \cap R_{j}} s_{i j}\right)\right)^{-1}$ and, in violation of Jensen's inequality, proceed under the basis of equality holding between these two entities. Under regional $p$ invariance, we then obtain $\mathbf{E}_{M_{t} \in \mathcal{M}_{t}}\left(\sum_{a_{i j} \in M_{t} \cap R_{j}} s_{i j}\right)=n_{j}\left|R_{j}\right|^{-1} \sum_{a_{i j} \in R_{j}} s_{i j}^{R F B}$. Substituting this expression into condition (b) in part (ii) of Proposition 4 we then obtain a within-region square-root rule for $s_{i j}$, which becomes a square-root rule within and across regions under $p$ -

\footnotetext{
${ }^{13}$ As discussed in footnote 12 , if $N\left|R_{j} \| A\right|^{-1}$ is not an integer for some $j$, then that $N\left|R_{j} \| A\right|^{-1}$ must be replaced in part (iv) of Corollary 1 with either $\left\lfloor N\left|R_{j}\right||A|^{-1}\right\lrcorner$ or $\left\lceil N\left|R_{j}\right||A|^{-1}\right\rceil$ as appropriate.
} 
invariance. Therefore, the rules for $s_{i j}$ in parts (iii) and (iv) of the Corollary deviate from square-root rules to the extent that $\mathbf{E}_{M_{t} \in \mathcal{M}_{i}}\left(\left(\sum_{a_{i j} \in M_{t} \cap R_{j}} s_{i j}\right)^{-1}\right)$ deviates from proportionality with $\left(\mathbf{E}_{M_{t} \in \mathcal{M}_{t}}\left(\sum_{a_{i j} \in M_{t} \cap R_{j}} s_{i j}\right)\right)^{-1}$.

Note that all the rules in Corollary 1 are monotonic within region in the sense that $s_{i j} \geq s_{i^{\prime} j} \Leftrightarrow$ $q_{i j} \geq q_{i^{\prime} j}$ for all $a_{i j}, a_{i^{\prime} j} \in R_{j}$ and for all $j \in J$; and that an equivalent condition holds on the $p_{i j t}$ at all times $t \in T^{\prime}$. If $C^{\prime}$ satisfies both of these conditions, we say it is regional monotonic. Rules that imply regional monotonicity seem the most relevant empirically, and we concentrate upon this class accordingly. We note, however, that AE may be satisfied by a range of less empirically plausible rules in which one of $s_{i j}$ or $p_{i j}$ is a strictly decreasing function of $q_{i j}$, and the other is an increasing function of $q_{i j}$ that increases faster than $\sqrt{q_{i j}}$.

\section{Application}

In this section we apply the theory of Section 2 to the case of the UNSC, the most powerful organ within the United Nations, with the authority to make legally binding resolutions to fulfil its mandate of maintaining international peace and security. To that end, it can suspend economic and diplomatic relations between countries, impose blockades, and authorise the use of armed force.

Under the present arrangements - which have been in place since 1965 - the UNSC is comprised of 15 members, of which five - China, France, Russia, the United Kingdom, and the United States - are ever-present and wield a veto on all non-procedural matters. The remaining ten members are elected NPMs who serve time-limited two-year terms. The ten NPM seats are divided between five regional caucusing groups: one country from Eastern Europe (EE); two countries from each of the Western European and Others Group (WEOG), the Latin America and Caribbean Group (GRULAC - el Grupo Latinoamericano y Caribeño) and Asia; and three countries from Africa. ${ }^{14}$

Both country and regional perspectives on equity are frequently cited by those that propose reform (e.g., Russett, O’Neill and Sutterlin, 1996; Hammer, 2002; Schwartzberg, 2003;

\footnotetext{
${ }^{14}$ See Appendix 2 for the full membership of each of the regional groups (excluding PMs). Of the PMs, China is a member in Asia, Russia in EE, and France and the UK in the WEOG. Technically, the United States is not a member of any regional group, but it attends meetings of the WEOG as an observer and is considered to be a member of that group for electoral purposes (UN, 2012). For the purposes of this paper, therefore, we give the United States membership in the WEOG.
} 
Annan, 2005; Blum, 2005). From the country perspective, it is commonly argued that the right of veto of the five PMs gives these countries too great an influence; and that other countries are more deserving of PM status than are France and the UK (Germany and Japan both have larger populations and economies, and contribute more to the UN regular budget). ${ }^{15}$ Nearly all governments wish to abolish or limit the right of veto, which is viewed as an unfair and anachronistic legacy of the Second World War (Fassbender, 2004; Schwartzberg, 2003).

From the regional perspective it is argued that Africa and Asia are under-represented as together they account for around 75 per cent of the UN population, but are allocated only 20 per cent of the PM seats, and 50 per cent of the NPM seats; and that there exists a broader representational imbalance between the north - defined in Zifcak (2006: footnote 9) as comprising EE, and the WEOG - and south (Africa, Asia and the GRULAC).

In the absence of a formal theoretical framework for measuring the equitability of CVGs, or for addressing issues relating to region- and country-specific notions of equity, existing quantitative analyses are unable to directly assess these claims. Instead, extant studies use the voting power of a PM relative to a NPM as an informal indicator of equitability (see, e.g., Hosli et al., 2011; O’Neill, 1996; Strand and Rapkin, 2011; Straffin, 1993: 180). The theoretical framework of Section 2 permits, for the first time, a formal quantitative assessment of the equitability of the UNSC for both individual countries and regions.

Another contribution with respect to the extant literature is the choice of decision rule to represent the UNSC. The studies above, and many precursors in the literature (e.g., Shapley and Shubik, 1954; Straffin, 1983), model the UNSC decision rule as a binary rule in which members can vote only for or against a resolution. In the UNSC, however, the UN Charter states that decisions over non-procedural matters are made by an affirmative vote of nine or more members, including the concurring votes of the PMs. A "concurring" vote has come to be understood, in practice, as either an affirmative vote or an abstention (see Blum, 2005: 636), so a negative vote by a PM is distinct from an abstention. As commented by Felsenthal and Machover (1997c: 348), this feature of the UNSC decision rule implies that it "cannot be faithfully represented" as a binary decision rule. ${ }^{16}$ We therefore allow here for a ternary

\footnotetext{
${ }^{15}$ As of 2012, Japan contributes 12.5 per cent of the UN regular budget, Germany 8.0 per cent, the UK only 6.6 per cent, and France only 6.1 per cent (UN Secretariat, 2011).

${ }^{16}$ The same point is also made in Freixas and Zwicker (2003).
} 
decision rule, which is a map from the set $\{-1,0,1\}^{N}$ to the set $\{-1,1\}$, satisfying the monotonicity conditions set out in Felsenthal and Machover (1997c: Definition 2.2).

\subsection{Measuring Deviations from Equitability}

It is desirable to be able to measure, in an objective sense, the proximity of the CVG representing the UNSC, $C_{\mathrm{UNSC}}=\left\{C_{\mathrm{UNSC}, t}\right\}_{t \in T}$, to each equity concept at time $t_{0}$, where we set $t_{0}=2012$. To this end, we adopt the metric $d(\mathbf{X}, \mathbf{Y})=1 / 2 \sum\left|X_{i}-Y_{i}\right|$, where $\mathbf{X}$ and $\mathbf{Y}$ are unitvectors, which corresponds to the index of distortion used in Felsenthal and Machover (2004, 2007), and commonly attributed to Loosemore and Hanby (1971).

Let $P M$ be the set of PMs and $O M$ be the set of the remaining 188 "ordinary" members. We model the UNSC in the framework of the previous section by setting $s_{i j}=\beta_{\mathrm{PM}}$ for $a_{i j} \in P M, s_{i j}$ $=\beta_{\mathrm{NPM}}$ for $a_{i j} \in O M$, and $w\left(z_{j t}\right)=\left(\sum_{j \in J} z_{j t}\right)^{-1}=1$. As PMs are guaranteed allocation to the UNSC, we have $p_{i j t}=1$ for these countries. We then obtain $\alpha_{i j t}=\beta_{\mathrm{PM}}$ for $a_{i j} \in P M$ and $\alpha_{i j t}=$ $p_{i j} \beta_{\mathrm{NPM}}$ for $a_{i j} \in O M$. From part ( $i$ ) of Proposition 1 and condition (b) of part (ii) of Proposition 2, we define proximity measures on $C_{\mathrm{UNSC}}^{\mathrm{u}}$ (as at 2012) with respect to our two country-based equity measures as

$$
A E=1-\mathbf{E}_{t \in T^{\prime}}\left(d\left(\boldsymbol{\alpha}_{t}, \boldsymbol{\alpha}^{\mathrm{AE}}\right)\right) ; \quad P E=1-d\left(\boldsymbol{\beta}, \boldsymbol{\beta}^{\mathrm{PE}}\right) ;
$$

where $\boldsymbol{\alpha}_{t}$ is the scaled $|A| \times 1$ unit vector of the $\alpha_{i j t} ; \boldsymbol{\alpha}^{\mathrm{AE}}=\boldsymbol{\beta}^{\mathrm{PE}}$ is the scaled $|A| \times 1$ unit vector of the $\sqrt{q_{i j}}$; and $\boldsymbol{\beta}$ is the scaled $|A| \times 1$ unit vector of the UNSC voting powers. ${ }^{17}$ Note that these two measures lie on the unit interval, with unity indicating maximal proximity, and zero indicating the minimum possible proximity.

To define an analogous proximity measure for $C_{\mathrm{UNSC}}^{\prime}$ with respect to RE we note that we may write

$$
\sum_{a_{i j} \in M_{t} \cap R_{j}} \beta_{i j t}=n_{j, \mathrm{PM}} \beta_{\mathrm{PM}}+\left(n_{j}-n_{j, \mathrm{PM}}\right) \beta_{\mathrm{NPM}}
$$

Hence, using part (iii) of Proposition 1, we define

$$
R E=1-d\left(\sum \boldsymbol{\beta}, \boldsymbol{\beta}^{\mathrm{RE}}\right),
$$

\footnotetext{
${ }^{17}$ In the case of the UNSC we have $w(\cdot)$ of the form in condition $(a)$ of part (ii) of Proposition 2. Hence, for PE, it is sufficient to test for proximity to condition $(b)$.
} 
where $\Sigma \boldsymbol{\beta}$ is the scaled $|J| \times 1$ unit vector of the right-side of (1), and $\boldsymbol{\beta}^{\mathrm{RE}}$ is the scaled $|J| \times 1$ unit vector of the $\sum_{a_{i j} \in R_{j}} \sqrt{q_{i j}}$. To measure proximity to each of our two concepts of the firstbest we examine the average proximity to the relevant two equity concepts:

$$
\begin{gathered}
C F B=1-\frac{1}{2}\left(\mathbf{E}_{t \in T^{\prime}}\left(d\left(\boldsymbol{\alpha}_{t}, \boldsymbol{\alpha}^{\mathrm{AE}}\right)\right)+d\left(\boldsymbol{\beta}, \boldsymbol{\beta}^{\mathrm{PE}}\right)\right)=\frac{1}{2}(A E+P E) \\
R F B=1-\frac{1}{2}\left(\mathbf{E}_{t \in T^{\prime}}\left(d\left(\boldsymbol{\alpha}_{t}, \boldsymbol{\alpha}^{\mathrm{AE}}\right)\right)+d\left(\sum \boldsymbol{\beta}, \boldsymbol{\beta}^{\mathrm{RE}}\right)\right)=\frac{1}{2}(A E+R E) .
\end{gathered}
$$

\subsection{Computing equity measures}

As is by now conventional in the literature, we adopt the normalised Banzhaf index as our measure of relative a-priori voting power. Note, however, that we adopt the ternary interpretation of the normalised Banzhaf index, as set out by Felsenthal and Machover (1997c), rather than the more conventional binary interpretation. We compute the ternary normalised Banzhaf index using the method of generating functions (see, e.g., Freixas, 2012). In this way we obtain the relative voting power of a $\mathrm{PM}$ as $\beta_{\mathrm{PM}} \approx 0.10$ and $\beta_{\mathrm{NPM}} \approx 0.05$, implying that a PM has almost exactly twice the voting power of a NPM. ${ }^{18}$

Using country population data for 2012 we compute the vectors $\boldsymbol{\beta}^{\mathrm{PE}}, \Sigma \boldsymbol{\beta}$, and $\boldsymbol{\beta}^{\mathrm{RE}}$ defined in Section 3.1. ${ }^{19}$ To compute $\boldsymbol{\alpha}^{\mathrm{AE}}$, however, requires knowledge of the $p_{i j t}$ for $a_{i j} \in O M$. We specify the allocation process $P_{\mathrm{UNSC}}$ by assigning each country in $O M$ with a probability, $\rho_{i j} \in$ $[0,1]$, where $\sum_{a_{i j} \in R_{j}} \rho_{i j}=1$, with which it will be allocated to the UNSC if it is in competition with all members of its region and if only a single seat is being allocated.

We use empirical estimates of the $\rho_{i j}$ that apply in the actual UNSC. These are taken from our earlier analysis, Dreher et al. (in press), in which we empirically estimate the systematic determinants of the election of OMs to the UNSC, accounting for the two-stage process by which such members are presently elected. ${ }^{20}$ There we show that three country characteristics systematically predict UNSC election: population, gross national income per capita, and waiting time since last serving on the UNSC. The estimated co-efficients for these three

\footnotetext{
${ }^{18}$ Note, in contrast, that if the UNSC decision rule is modeled as binary, then we obtain $\beta_{\mathrm{PM}} \approx 0.167$ and $\beta_{\mathrm{NPM}} \approx$ 0.017, which implies that a PM has around ten times as much voting power as a NPM.

19 Population data are from the CIA World Factbook (https://www.cia.gov/library/publications/the-worldfactbook/index.html\#).

${ }^{20}$ In the first stage, the regions make nominations to the UNGA and, in the second stage, the UNGA votes. See, e.g., Dreher et al. (in press) for a detailed account.
} 
variables can be used in a straightforward way to compute estimates of the $\rho_{i j}{ }^{21}$ The resulting estimates are listed in Appendix 2.

In practice, the UNGA simultaneously allocates OMs to the UNSC. For the purposes of developing a tractable simulation model, however, we suppose that when the UNGA must elect more than one NPM from the same region in a given year, countries are elected sequentially, one-by-one. Hence, if there are two seats to be allocated to members of region $j$, then, in each of two rounds, there is a new realisation of a random variable that, if all countries in the region are competing for the seat, elects country $a_{i j}$ with probability $\rho_{i j}$. Because, however, UNSC rules prohibit countries from having dual membership, if the same country is elected in both rounds the process is repeated again in full. This continues until distinct countries are elected.

What does this procedure imply for the relationship between the $\rho_{i j}$ and the $p_{i j t}$ ? In a given year, a first set of countries, those half-way through their two-year term, gain automatic renewal of their NPM status in the following year $\left(R_{t}\right)$; a second set of countries, $I_{t}$, are those ineligible for election to the UNSC in the following year (UNSC rules prohibit NPMs from seeking immediate re-election); and a final set of countries is eligible for election to the $\operatorname{UNSC}\left(E_{t}\right)$. Hence we can write

$$
p_{i j t}\left\{\begin{array}{cl}
=0 & \text { if } a_{i j} \in I_{t} \\
\in(0,1) & \text { if } a_{i j} \in E_{t} \\
=1 & \text { if } a_{i j} \in R_{t} .
\end{array}\right.
$$

For $a_{i j} \in E_{t}$, let $p_{i j t}^{n}$ denote $p_{i j t}$ when $n$ NPM seats are being elected in region $j$, in which case

$$
p_{i j t}^{0}=0 ; \quad p_{i j t}^{1}=\frac{\rho_{i j}}{\sum_{a_{i j} \in E_{j t}} \rho_{i j}} ; \quad p_{i j t}^{2}=\frac{2 p_{i j t}^{1}\left(1-p_{i j t}^{1}\right)}{1-\sum_{a_{i j} \in E_{j t}}\left(p_{i j t}^{1}\right)^{2}} .
$$

Note that the numerator of $p_{i j t}^{2}$ is the binomial probability of observing a distinct country pair containing $a_{i j}$, and that the denominator corrects for the impossibility of a country obtaining dual UNSC membership.

\footnotetext{
${ }^{21}$ Because the Dreher et al. dataset ends at 2006, we obtain estimates of country population and gross national income per capita (current US\$) for 2012 from the CIA World Factbook (see footnote 19). We update Dreher et al.'s variable measuring waiting time since last serving on the UNSC to 2012 using historical UNSC membership data from the UNSC Web site (http://www.un.org/Docs/sc). To produce the estimates in Appendix 2 , these data, along with the co-efficient values for population, gross national income per capita, and waiting time since last serving on the UNSC reported in their Table 3a, are fed into their equation (5), where we assume that the sum in the denominator is over all countries in the region (i.e., their " $E_{j t}$ " - the set of countries competing for the seat - is assumed to be $R_{j t}$ ).
} 


\subsection{Simulating the UNSC}

The complexity of $P_{\mathrm{UNSC}}$ precludes analytical derivation of $\mathbf{E}_{t \in T^{\prime}}\left(d\left(\boldsymbol{\alpha}_{t}, \boldsymbol{\alpha}^{\mathrm{AE}}\right)\right)$. We therefore compute a finite-sample estimate of this statistic from the realisation (via computer simulation) of a CVG, $C_{\mathrm{UNSC}}^{\Omega}$, which is the finite-repetition analogue of $C_{\mathrm{UNSC}}^{\mathrm{\prime}}$ on $t \in \Omega(\Omega$ a finite set). For the purposes of simulation, we choose $\Omega$ to be the set of natural numbers from one to $100,000 .^{22}$

We adopt the same pattern of elections as occurs in the present UNSC: the term of the single EE NPM begins in even years. The two NPMs of the WEOG begin their terms in odd years. The terms for the two NPMs of the GRULAC are staggered; one is elected each year. The Asia's two NPM seats are similarly staggered. The three Africa NPM seats are also staggered with two terms beginning in even years and one term beginning in odd years.

\subsection{Results}

Simulating the UNSC according to the approach of the previous section, our proximity measures are found as

$$
\begin{gathered}
A E=0.45 ; \quad P E=0.66 ; \quad R E=0.70 ; \\
C F B=0.56 ; \quad R F B=0.68 .
\end{gathered}
$$

These measures show that the UNSC is $(i)$ more inequitable from a country perspective than from a regional perspective; and (ii) more inequitable from an ex-ante (procedural) perspective than from an ex-post (outcome) perspective.

To explain these findings, in Appendix 3 we show country-by-country measures for each of our three equity concepts. Whereas our proximity measures above are based upon absolute deviations, the measures reported in Appendix 3 report individual relative deviations from each of our equity concepts. In particular, we report the measure $R$ where

\footnotetext{
${ }^{22}$ Precisely, we realise marginally more than 100,000 periods, but discard the very earliest periods. This is necessary as we begin with a UNSC containing the five PMs and ten vacant seats. In each period we elect five new NPMs, hence, it is not until the completion of the election in period two that there remain no vacant seats on the elected UNSC. We discard the first four periods, which corresponds to twice the term length of a NPM, as, in all periods beyond the fourth, the elected UNSC contains no vacant seats, and eligibility for election to the UNSC does not depend upon whether a country was elected to the UNSC in either of periods one or two (when, abnormally, $\left.I_{t}=\varnothing\right)$.
} 


$$
R_{i j}^{\mathrm{AE}}=\frac{\mathbf{E}_{t \in \Omega}\left(\alpha_{i j t}\right)}{\alpha_{i j}^{\mathrm{AE}}} ; \quad R_{i j}^{\mathrm{PE}}=\frac{\beta_{i j}}{\beta_{i j}^{\mathrm{PE}}} ; \quad R_{j}^{\mathrm{RE}}=\frac{(\Sigma \beta)_{j}}{\beta_{j}^{\mathrm{RE}}} .
$$

We begin with an analysis of the UNSC from a country perspective. The conclusions are, however, sensitive to whether this is done from an ex-ante or ex-post perspective. Taking the ex-post perspective first, the relevant equity concept is PE. The relatively middling score achieved by the UNSC largely reflects two factors. First, within the PM and NPM categories, each country is awarded the same voting power regardless of its population. As may be seen in the first column of the table in Appendix 3, a consequence is that, within each membership category, the most populous countries receive a voting power that is much too low. The most extreme example is India, which receives only 10.7 per cent of its voting power under PE. In spite of receiving the voting power of a PM, China receives only 21 per cent of its voting power under PE. Two further PMs - Russia and the United States - are also substantially underweighted. In the remaining regions, countries such as Brazil (27 per cent), Nigeria (30 per cent), Germany (41 per cent) and Ukraine (56 per cent) also find themselves substantially under-represented according to PE.

An analogous consequence, which principally manifests itself among the NPMs, is that the least populous countries receive a voting power that is much too high. The most extreme example is Tuvalu, which receives 37.9 times its voting power under PE. In the remaining regions, countries such as San Marino (21 times), St. Kitts and Nevis (16 times), The Seychelles (13 times), and Montenegro (5 times) also find themselves substantially overrepresented under PE.

The second factor is the division of voting power between the five PMs and the remaining UN membership. It is conventionally assumed that this division is too favourable to the PMs, but we conclude the opposite. Consistent with our comments regarding the underweighting of China, the United States, and Russia above, we calculate the total voting power of the PMs to be only 47 per cent of that consistent with PE. The remaining UN members therefore receive, on average, too much voting power on the UNSC under PE.

When we repeat the same analysis from an ex-ante perspective, however, we observe some important differences. For instance, the balance of power between $P M$ and $O M$ remains a problem, but now because far too much expected voting power is given to citizens of PM countries. On average, the PMs wield around 4.6 times too much expected voting power: the UK, in particular, wields some 9.6 times more expected voting power than that consistent 
with $\mathrm{AE}$, and even China wields around twice too much expected voting power. How can the PMs be simultaneously under-represented according to PE, and over-represented according to $\mathrm{AE}$ ? The answer lies in the observation that PM countries are always able to cast their vote in Stage 3, whereas all other countries can do so only periodically. It is the combination of their right to be ever-present, together with their right of veto, which gives the PMs a disproportionately large share of the expected voting power.

Accordingly, ordinary members suffer a deficit of expected voting power. Therefore, only a small proportion of such countries exceed their expected voting power under AE, and the major individual deviations are for countries that receive too little expected voting power. For instance, under the estimated membership distribution in Appendix 2, Dominica receives just 0.6 per cent of its expected voting power under AE. In other regions, countries such as Chad (11 per cent), Samoa (1 per cent), Montenegro (3 per cent) and Liechtenstein (0.7 per cent) also receive much too little expected voting power.

In summary, the current UNSC deviates significantly from both the AE and PE concepts. The deviations from $\mathrm{AE}$ are the more severe, because PMs enjoy the highest voting power and the highest allocation probability, whereas these should be traded-off under AE. Whether the PMs are favoured hinges, however, on whether an ex-ante or ex-post perspective is adopted: PMs obtain decisively too much expected voting power ex-ante, but too little realised voting power ex-post. Accordingly, proposals for reform of the UNSC should not seek to erode the voting power of the existing PMs when members of the UNSC (indeed, this should be increased), but should instead focus upon eroding the right of these countries to be everpresent on the UNSC.

We now analyse the UNSC from a regional perspective using the RE concept. We find evidence in the third column of the table in Appendix 3 to support the widely-made claim that Africa and Asia are under-represented. We find that Asia is the most under-represented region, with only 55 per cent of its voting power under RE, closely followed by Africa with just 57 per cent. The GRULAC is also under-represented, but by a smaller margin - it receives 76 per cent of its voting power under RE. Balancing off the under-represented regions are the WEOG - which receives around 2.6 times its voting power under RE, and EE, which is over-represented by 61 per cent. These results imply the existence of a substantial north/south inequity. We find that, overall, the south receives just 60 per cent of its voting power under RE. Accordingly, proposals for reform of the UNSC should principally seek to shift voting power away from the WEOG, and towards Asia and Africa. 
Last, we use our theoretical framework to address some of the remaining issues raised by reformers. Should some countries be ever-present on the UNSC? If so, which ones? Under the CFB concept the answer is negative: all countries receive a common allocation probability $p=N|A|^{-1}<1$. The RFB concept does not preclude ever-present members, but only if the country is sufficiently populous. To see this, note that within the class of regional monotonic $C^{\prime}$ satisfying RFB, the maximal variation in the $p_{i j t}$ across countries is achieved under a flat rule for voting power. In this case, by Corollary 1, the allocation probabilities are set such that $p_{i j}^{\mathrm{RFB}} \propto_{A} \sqrt{q_{i j}}$, in which case a country is ever-present if

$$
p_{i j}^{\mathrm{RFB}}=N \frac{\sqrt{q_{i j}}}{\sum_{a_{i j} \in A} \sqrt{q_{i j}}} \geq 1 .
$$

We find, however, that no country is sufficiently populous to meet this condition. Rather, in this case, China would be represented on the UNSC most often, obtaining membership in around 73 out of every 100 years. India would be represented next most often, obtaining membership in around seven years in every ten. The United States would qualify for membership in only around seven years in every twenty, while the UK and France would qualify for membership in only around four in every 25 years.

Our first-best concepts can also shed some light on whether the right of veto should be abolished and, if not, which countries should exercise a veto. A direct analysis is not feasible, however, for, even when we know the first-best voting power of each country, this information is insufficient to determine whether a country exercises a veto. The difficulty is that voting power indices mix two distinct concepts - the power to prevent action by voting against a resolution, and the power to initiate action by voting for a resolution (Coleman, 1971). Hence, the degree of preventative power associated with a given vector of voting powers is a-priori unknown.

By Corollary 1, under RFB and $\beta$-invariance council members receive a common voting power $\beta=N^{-1}$. This case is sufficiently simple that we can conclude that either all council members exercise a veto (under a unanimity decision rule), or none do. Hence the RFB concept does not preclude a veto right. Under the CFB concept - in which voting powers are set such that $\beta_{i j} \propto_{A} \sqrt{q_{i j}}$ - we can instead examine which, if any, countries obtain a voting power that is at least as large as that currently wielded by a PM. Under CFB, countries do not obtain the same voting power every time they are allocated to the UNSC as the $w_{j t}$ are random 
variables. To investigate this case we therefore examine each of the 100,000 realised $M_{t}$ from the simulation of $C_{\mathrm{UNSC}}^{\Omega}$ under the CFB voting powers. We measure the proportion of a country's appearances on the UNSC for which it votes with a power $\beta_{i j}>\beta_{\mathrm{PM}}$ under CFB. We find that, in our 100,000 realisations, China and India always receive a voting power higher than $\beta_{\mathrm{PM}}$ under $\mathrm{CFB}$. China, in particular, receives, on average, a voting power of around 0.23 , which is slightly more than double $\beta_{\mathrm{PM}}{ }^{23}$

In summary, we do not find clear support for the abolition of the veto: RFB does not preclude veto countries, and the CFB concept suggests that some countries warrant more voting power than currently received by a PM. Three points are of note, however: first, our first-best concepts imply that no country should have a veto and be ever-present on the UNSC. Second, the CFB concept suggests that if a veto right is to be allocated to five countries it should be the five most populous: China, India, the United States, Indonesia, and Brazil. Thus we agree with reformers that, if the right of veto is to remain, attention should be focused upon its allocation. As, however, we consider democratic ideals rather than economic might, or peacekeeping contributions, our analysis does not suggest that either Germany or Japan should be the recipients of a veto. ${ }^{24}$ Last, a possible avenue for reform based on our findings may be for the PMs to trade-off extra voting power when a UNSC member with the loss of the right to be ever-present.

The final issue we address is how the 15 UNSC seats should be divided between regions. According to Proposition 4, the CFB concept implies that the $n_{j}$ should be set proportional to $\left|R_{j}\right|$, i.e., four each to Africa and Asia, three to the GRULAC, and two each to EE and the WEOG. The RFB concept is consistent with a number of rules for $n_{j}$. Under $p$-invariance RFB yields the same rule as under $\mathrm{CFB}$, but, under $\beta$-invariance, RFB requires $n_{j} \propto_{J}$ $\sum_{a_{i j} \in R_{j}} \sqrt{q_{i j}}$. Relative to the rule for $n_{j}$ under CFB, this rule gives one extra seat to Asia (five seats), one less to the GRULAC (two seats), and leaves the entitlements of the remaining regions unchanged. Thus the WEOG, with four seats in the present UNSC, has twice its entitlement under either first-best concept, while Asia and Africa - which both receive three seats - are under-represented by at least one seat (and Asia by two seats under the RFB rule

\footnotetext{
${ }^{23}$ The remaining countries that sometimes (but not always) receive $\beta_{i j}>\beta_{\mathrm{PM}}$ are the United States (77 per cent of council appearances), Indonesia (33 per cent), Brazil (3.5 per cent), Pakistan ( 0.6 per cent), Russia (0.06 per cent) and Nigeria (0.04 per cent).

${ }^{24}$ As seen in Appendix 3, Japan and Germany - like the PMs - are heavily under-represented according to PE. Both countries have historically achieved election to the UNSC on a regular basis, however, hence their representation under AE tells a different story. Japan's expected voting power is roughly in accordance with AE, while Germany is actually over-represented by 65 per cent under AE.
} 
above).

\section{Conclusion}

The Councils of the United Nations - the UNSC and ECOSOC - play an important role in global wealth and security. Yet, to our knowledge, no previous analysis has developed formal equity principles for the analysis of such bodies, in which only a subset of member countries may vote at a point in time.

In this paper we develop a new class of voting game we term a council voting game. We then develop three democratic equity concepts for this new class of game. These three concepts differ according to whether equity is in an ex-ante (or procedural) sense, or in an ex-post (or outcome) sense; and whether council members are viewed as regional representatives, or solely as representatives of themselves. Fundamental trade-offs exist between these concepts, for if a CVG is PE then it cannot be RE. The AE concept is consistent with either PE or RE on their own, but even here the conditions required are stringent: either allocation probabilities must be equal across all countries (under the CFB concept) or a more general trade-off between voting power and allocation probability must hold (under the RFB concept).

We demonstrate the utility of our theoretical framework with an application to the UNSC. Significant degrees of inequity exist irrespective of the precise equity concept used, but we find that the UNSC is more inequitable in an ex-ante sense than in an ex-post sense, and more inequitable if countries are viewed as representing themselves, than if they are viewed as representing their region.

What do our findings imply for the ongoing debate on UNSC reform? First, we believe our framework clarifies the nature of the underlying trade-offs. For instance, simultaneous achievement of PE and RE is unfeasible; and, if realpolitik makes giving every country an equal probability of council allocation unfeasible, then some trade-off between $\mathrm{AE}$ and $\mathrm{PE}$ is unavoidable. Second, our analysis highlights that a successful reform of the UNSC must simultaneously address the distribution of voting power and the distribution of allocation probability, for attempting to achieve our equity concepts by changing only one or the other will lead to extreme outcomes. For instance, if the current allocation probabilities are retained, then our calculations show that attainment of $\mathrm{AE}$ requires that (tiny) countries such 
as Nauru, Micronesia, Palau, and San Marino receive a voting power well in excess of the current $\beta_{\mathrm{PM}}$ when a member of the UNSC, as compensation for being a member very infrequently.

The apparent tension between realpolitik and the first-best concepts we develop suggests that the latter should be understood as purely theoretical benchmarks against which to assess the equitability of the UNSC and the desirability of alternative reforms. While this in no way undermines the usefulness of these concepts, an avenue for future research might, therefore, be to investigate second-best rules that move a CVG as "close" as possible to our first-best benchmarks under an additional realpolitik constraint. While this idea must await a proper treatment, however, we hope the present contribution at least marks a first step in the analysis of democratic equitability in councils.

\section{References}

Annan, K.A. (2005). In Larger Freedom: Towards Development, Security and Human Rights for All, A/59/2005, New York: United Nations.

Banzhaf, J.F. (1968). "One man, 3.312 votes: A mathematical analysis of the Electoral College", Villanova Law Review 13: 304-332.

Blum, Y.Z. (2005). "Proposals for UN Security Council Reform", American Journal of International Law 99(3): 632-649.

Coleman J.S. (1971). "Control of collectivities and the power of a collectivity to act". In B. Lieberman (Ed.) Social Choice, pp. 269-300, New York: Gordon and Breach.

Cox, B. (2009). "United Nations Security Council reform: Collected proposals and possible consequences", South Carolina Journal of International Law and Business 6(1): 89-127.

De Cremer, D., Brockner, J., Fishman, A., van Dijke, M., van Olffen, W. and Mayer, D.M. (2010). "When do procedural fairness and outcome fairness interact to influence employees' work attitudes and behaviors? The moderating effect of uncertainty", Journal of Applied Psychology 95(2): 291-304.

Dixon, W.J. (1983). "The evaluation of weighted voting schemes for the United Nations General Assembly", International Studies Quarterly 27(3): 295-314.

Dreher, A., Gould, M., Rablen, M.D. and Vreeland, J.R. (in press). "The determinants of election to the United Nations Security Council", Public Choice. doi: 10.1007/s11127013-0096-4

Dunleavy, P. (2010). The Distribution of Power across Parties in Parliament, London: LSE Online.

Fassbender, B. (2004). "Pressure for Security Council reform", in D.M. Malone (Ed.), The UN Security Council: From the Cold War to the 21st Century, pp. 341-356, Colorado: Lynne Rienner.

Felsenthal, D.S. and Machover, M. (1997a). "The weighted voting rule in the EU's Council of Ministers, 1958-95: Intentions and outcomes", Electoral Studies 16(1): 33-47.

Felsenthal, D.S. and Machover, M. (1997b). Enlargement of the EU and Weighted Voting in its Council of Ministers, London: LSE Online.

Felsenthal, D.S. and Machover, M. (1997c). "Ternary voting games", International Journal of Game Theory 26(3): 335-351. 
Felsenthal, D. and Machover, M. (1998). The Measurement of Power: Theory and Practice, Problems and Paradoxes, Cheltenham: Edward Elgar.

Felsenthal, D.S. and Machover, M. (2001). "The Treaty of Nice and qualified majority voting", Social Choice and Welfare 18(3): 431-464.

Felsenthal, D.S. and Machover, M. (2003). "The voting power approach: Response to a philosophical reproach", European Union Politics 4(4): 473-479.

Felsenthal, D.S. and Machover, M. (2004). "Analysis of QM rules in the draft constitution for Europe proposed by the European Convention, 2003", Social Choice and Welfare 23(1): $1-20$.

Felsenthal, D. and Machover, M. (2007). Analysis of QM Rule Adopted by the Council of the European Union, London: LSE Online.

Franck, T.M. (2003). "What happens now? The United Nations after Iraq", American Journal of International Law, 97(3): 607-620.

Freixas, J. (2012). "Probabilistic power indices for voting rules with abstention", Mathematical Social Sciences 64(1): 89-99.

Freixas, J. and Zwicker, W.S. (2003). "Weighted voting, abstention, and multiple levels of approval", Social Choice and Welfare 21(3): 399-431.

Hammer, C. (2002). "Reforming the U.N. Security Council: Open letter to U.N. Secretary General Kofi Annan", Florida Journal of International Law 15(2): 261-272.

Hosli, M.O., Moody, O., O’Donovan, B., Kaniovski, S. and Little, A.C.H. (2011). "Squaring the circle? Collective and distributive effects of United Nations Security Council reform", Review of International Organizations 6(2): 163-187.

Kirsch, W. and Langner, J. (2011). "The fate of the square root law for correlated voting", Paper presented at the Voting Power in Practice Symposium, London.

Konovsky, M.A. (2000). "Understanding procedural justice and its impact on business organizations", Journal of Management 26(3): 489-511.

Lai, B. and Lefler, V.A. (2009). "U.N. Security Council nonpermanent membership: equitable distribution for equitable representation?", working paper, Midwest Political Science Association.

Laruelle, A. and Widgrén, M. (1998), "Is the allocation of power among EU states fair?", Public Choice 94(3-4): 317-340.

Leech, D. (2002a). "Designing the voting system for the EU Council of Ministers", Public Choice 113(3-4): 437-464.

Leech, D. (2002b). "Voting power in the governance of the International Monetary Fund", Annals of Operations Research, 109(1-4): 375-397.

Leech, D. and Leech, R. (2005). "Voting power in the Bretton Woods institutions", Homo Oeconomicus 22(4): 1-23.

Leech, D. and Leech, R. (2013). "A new analysis of a priori voting power in the IMF: Recent quota reforms give little cause for celebration". In M.J. Holler and N. Nurmi (Eds.) Power, Voting, and Voting Power: 30 Years After, pp. 389-410, Heidelberg: Springer.

Loosemore, J. and Hanby, V.J. (1971). "The theoretical limits of maximum distortion: Some analytic expressions for electoral systems", British Journal of Political Science 1(4): 467477.

Malone, D. (2000). "Eyes on the prize: The quest for nonpermanent seats on the UN Security Council", Global Governance 6(1): 3-23.

Manno, C.S. (1966). "Selective weighted voting in the UN General Assembly: Rationale and methods", International Organization 20(1): 37-62.

McLean, I., McMillan, A. and Leech, D. (2005). "Duverger's law, Penrose's power index and the unity of the UK", Political Studies 53(3): 457-476.

Miller, N.R. (2009). "A priori voting power and the U.S. Electoral College", Homo 
Oeconomicus 26(3/4): 341-380.

Napel, S. and Widgrén, M. (2006). "The inter-institutional distribution of power in EU codecision", Social Choice and Welfare 27(1): 129-154.

Newcombe, H., Wert, J. and Newcombe, A. (1971). "Comparison of weighted voting formulas for the United Nations", World Politics 23(3): 452-492.

O’Neill, B. (1996). "Power and satisfaction in the United Nations Security Council", Journal of Conflict Resolution 40(2): 219-237.

Penrose, L.S. (1946). "The elementary statistics of majority voting", Journal of the Royal Statistical Society 109(1): 53-57.

Rapkin, D.P. and Strand, J.R. (2006). "Reforming the IMF's weighted voting system", The World Economy 29(3): 305-324.

Russett, B., O’Neill, B. and Sutterlin, J. (1996). "Breaking the Security Council restructuring logjam", Global Governance 2(1): 65-80.

Schwartzberg, J.E. (2003). "Entitlement quotients as a vehicle for United Nations reform", Global Governance 9(1): 81-114.

Shapley, L.S. and Shubik, M. (1954). "A method for evaluating the distribution of power in a committee system”, American Political Science Review 48(3): 787-792.

Straffin P.D. (1983) "Power indices in politics". In S.J. Brams, W.F. Lucas and P.D. Straffin (Eds.) Political and Related Models, pp. 256-321, New York: Springer.

Straffin, P.D. (1993). Game Theory and Strategy, Washington, DC: The Mathematical Association of America.

Strand, J.R. and Rapkin D.P. (2011). "Weighted voting in the United Nations Security Council: A simulation", Simulation \& Gaming 42(6): 772-802.

UN (2012). United Nations Regional Groups of Member States. New York: UN. Available: http://www.un.org/depts/DGACM/RegionalGroups.shtml.

UN Secretariat (2011). Assessment of Member States' Contributions to the United Nations Regular Budget for 2012, ST/ADM/SER.B/853, New York: United Nations.

Zifcak, S.M. (2006). "United Nations reform: Heading north or south?", Global Change, Peace \& Security 18(3): 135-152. 


\section{Appendix 1: Proofs}

Proof of Proposition 1: For a proof of Penrose's square-root rule (from which the Proposition follows) see Felsenthal and Machover (1998).

Proof of Lemma 1: If $p_{i j t} \propto_{A} f_{i j t}$ then $n_{j}=\sum_{a_{i j} \in R_{j}} p_{i j t} \propto_{J} \sum_{a_{i j} \in R_{j}} f_{i j t}$

\section{Proof of Proposition 2}

(i) Under AE we have $\alpha_{i j t}=p_{i j t} s_{i j} \mathbf{E}_{M_{t} \in \mathcal{M}_{t}}\left(w_{j t}\right)$ and $\alpha_{i j t} \propto_{A} \sqrt{q_{i j}}$, so $p_{i j t} s_{i j} \propto_{A}\left(\mathbf{E}_{M_{t} \in \mathcal{M}_{t}}\left(w_{j t}\right)\right)^{-1} \sqrt{q_{i j}}$. For this condition to hold at all $t$ implies $p_{t}$-invariance (for the $p_{i j t}$ have a fixed sum across each region, so increasing one $p_{i j t}$ implies another must fall, leading to a violation of regional proportionality between these two countries). Hence $p_{i j} s_{i j} \propto_{A}\left(\mathbf{E}_{M_{t} \in \mathcal{M}_{t}}\left(w_{j t}\right)\right)^{-1} \sqrt{q_{i j}}$. Then $\left(\mathbf{E}_{M_{t} \in \mathcal{M}_{t}}\right.$ $\left.\left(w_{j t}\right)\right)^{-1} \sqrt{q_{i j}} \propto_{R} \sqrt{q_{i j}}$ so $p_{i j} s_{i j} \propto_{R} \sqrt{q_{i j}}$. Now suppose $p_{i j} s_{i j} \propto_{R} \sqrt{q_{i j}}$ then there exists a $w(\cdot)$ such that $p_{i j} s_{i j} \propto_{A}\left(\mathbf{E}_{M_{t} \in \mathcal{M}_{t}}\left(w_{j t}\right)\right)^{-1} \sqrt{q_{i j}}$, which is AE.

(ii) Under (a) we have $w_{j t} \propto_{A}\left(\sum_{a_{i j} \in M_{t}} s_{i j}\right)^{-1}$, hence $s_{i j} \propto_{M} \beta_{i j t}$. Then, by condition $(b), s_{i j} \propto_{M} \beta_{i j t}$ $\propto_{M} \sqrt{q_{i j}}$, which is PE. Now suppose $\beta_{i j t} \propto_{M} \sqrt{q_{i j}}$ holds, which implies condition $(a)$. Then $\beta_{i j t}$ $\propto_{M} s_{i j}$, hence $s_{i j} \propto_{M} \sqrt{q_{i j}}$, which implies $s_{i j} \propto_{A} \sqrt{q_{i j}}$.

(iii) We have $\sum_{a_{i j} \in M_{t} \cap R_{j}} \beta_{i j t} \propto_{J} \sum_{a_{i j} \in R_{j}} \sqrt{q_{i j}}$ by construction. Conversely, suppose we have $\sum_{a_{i j} \in M_{t} \cap R_{j}} \beta_{i j t} \propto_{J} \sum_{a_{i j} \in R_{j}} \sqrt{q_{i j}}$, then $\sum_{a_{i j} \in M_{t} \cap R_{j}} w_{j t} s_{i j} \propto_{J} \sum_{a_{i j} \in R_{j}} \sqrt{q_{i j}}$. As this condition must hold for arbitrary $s_{i j} \geq 0$, it implies that $w\left(z_{j t}\right)$ is of the form $w\left(z_{j t}\right)=x_{j}\left(z_{j t}\right)^{-1}$, where $x_{j} \propto_{J} \sum_{a_{i j} \in R_{j}} \sqrt{q_{i j}}$. Then the condition that $\sum_{a_{i j} \in M_{t}} w_{j t} s_{i j}=1$ implies $\sum_{a_{i j} \in M_{t}} x_{j}=1$.

Proof of Proposition 3: Under RE we have $\sum_{a_{i j} \in M_{t} \cap R_{j}} \beta_{i j t} \propto_{J} \sum_{a_{i j} \in R_{j}} \sqrt{q_{i j}}$. Under PE we have $\beta_{i j t}$ $\propto_{M} \sqrt{q_{i j}}$, hence $\sum_{a_{i j} \in M_{t} \cap R_{j}} \beta_{i j t} \propto_{J} \sum_{a_{i j} \in M_{t} \cap R_{j}} \sqrt{q_{i j}}$. For both conditions to hold we must have $\sum_{a_{i j} \in R_{j}} \sqrt{q_{i j}} \propto_{J} \sum_{a_{i j} \in M_{t} \cap R_{j}} \sqrt{q_{i j}}$. For this to hold $\sum_{a_{i j} \in M_{t} \cap R_{j}} \sqrt{q_{i j}}$ must be non-random, but this contradicts the assumptions of Section 2.2.

\section{Proof of Proposition 4}

(i) Conditions ( $a$ ) and (c) yield PE by part (ii) of Proposition 2. Then, by condition $(a)$ we have $\mathbf{E}_{M_{t} \in \mathcal{M}_{t}}\left(w_{j t}\right) \propto_{A} s_{i j}$, hence $\alpha_{i j t} \propto_{A} p_{i j t} s_{i j}$. By condition $(b)$ we have $\alpha_{i j t} \propto_{A} p_{i j} s_{i j} \propto_{A} s_{i j}$ so, by (c), we obtain $\alpha_{i j t} \propto_{A} p_{i j} s_{i j} \propto_{A} \sqrt{q_{i j}}$, which is AE. Now suppose AE and PE hold. Then, as $(a)$ must hold for PE, we have $\alpha_{i j t}=p_{i j t} s_{i j} \mathbf{E}_{M_{t} \in \mathcal{M}_{t}}\left(w_{j t}\right) \propto_{A} p_{i j t} s_{i j} \propto_{A} \sqrt{q_{i j}}$, which implies that $p_{i j t} s_{i j}$ must be time invariant, i.e., $\alpha_{i j t} \propto_{A} \sqrt{q_{i j}}$. By PE it also holds that $s_{i j} \propto_{A} \sqrt{q_{i j}}$, which is condition $(c)$ : both conditions hold if and only if condition $(b)$ is satisfied.

(ii) We have $\alpha_{i j t}=p_{i j t} s_{i j} \mathbf{E}_{M_{t} \in \mathcal{M}_{t}}\left(w_{j t}\right)$. Under AE $p_{i j t} s_{i j} \mathbf{E}_{M_{t} \in \mathcal{M}_{t}}\left(w_{j t}\right) \propto_{A} \sqrt{q_{i j}}$. Then substituting for $w_{j t}$ using condition $(a)$ yields condition $(b)$. 
Appendix 2: Estimated $\rho_{i j}(t=2012)$

\begin{tabular}{|c|c|c|c|c|c|c|c|c|c|}
\hline \multicolumn{2}{|l|}{ Africa } & \multicolumn{2}{|l|}{ Asia } & \multicolumn{2}{|l|}{$\mathrm{EE}$} & \multicolumn{2}{|c|}{ GRULAC } & \multicolumn{2}{|c|}{ WEOG } \\
\hline Algeria & 0.0860 & India & 0.47728 & Poland & 0.3681 & Brazil & 0.34235 & Germany & 0.28949 \\
\hline Morocco & 0.0501 & Japan & 0.12114 & Ukraine & 0.2470 & Mexico & 0.19389 & Turkey & 0.16346 \\
\hline Nigeria & 0.0497 & Pakistan & 0.09212 & Romania & 0.1122 & Venezuela & 0.16637 & Italy & 0.11347 \\
\hline Egypt & 0.0424 & Malaysia & 0.04707 & Hungary & 0.0591 & Argentina & 0.08081 & Spain & 0.07454 \\
\hline Ghana & 0.0384 & Republic of Korea & 0.04376 & Czech Republic & 0.0525 & Colombia & 0.04673 & Austria & 0.07041 \\
\hline Tunisia & 0.0377 & Indonesia & 0.03583 & Belarus & 0.0256 & Chile & 0.04251 & Netherlands & 0.04505 \\
\hline Tanzania & 0.0376 & Bangladesh & 0.02381 & Serbia & 0.0227 & Peru & 0.02556 & Canada & 0.03614 \\
\hline South Africa & 0.0336 & Singapore & 0.01899 & Bulgaria & 0.0191 & Ecuador & 0.01801 & Sweden & 0.03072 \\
\hline Zimbabwe & 0.0329 & Thailand & 0.01732 & Azerbaijan & 0.0178 & Uruguay & 0.01334 & Switzerland & 0.02616 \\
\hline Zambia & 0.0322 & Jordan & 0.01521 & Slovakia & 0.0145 & Cuba & 0.01019 & Ireland & 0.02483 \\
\hline Mozambique & 0.0319 & Philippines & 0.01487 & Croatia & 0.0112 & Dominican Republic & 0.00765 & Denmark & 0.02285 \\
\hline Kenya & 0.0319 & United Arab Emirates & 0.01314 & Republic of Moldova & 0.0078 & Honduras & 0.00712 & Belgium & 0.02184 \\
\hline Senegal & 0.0309 & Sri Lanka & 0.01113 & Georgia & 0.0074 & Costa Rica & 0.00605 & Finland & 0.01849 \\
\hline Mali & 0.0245 & Iran & 0.00657 & Albania & 0.0062 & Guatemala & 0.00538 & Portugal & 0.01692 \\
\hline Niger & 0.0226 & Saudi Arabia & 0.00630 & Lithuania & 0.0060 & Panama & 0.00484 & Norway & 0.01666 \\
\hline Cote d'Ivoire & 0.0220 & Kuwait & 0.00579 & Slovenia & 0.0052 & Trinidad and Tobago & 0.00458 & Australia & 0.01228 \\
\hline Guinea & 0.0218 & Myanmar & 0.00518 & Bosnia \& Herzegovina & 0.0047 & Guyana & 0.00415 & New Zealand & 0.01027 \\
\hline Congo & 0.0218 & Nepal & 0.00516 & Latvia & 0.0037 & Paraguay & 0.00409 & Greece & 0.00497 \\
\hline Ethiopia & 0.0213 & Qatar & 0.00462 & TFYR Macedonia & 0.0034 & Jamaica & 0.00381 & Israel & 0.00054 \\
\hline Angola & 0.0198 & Yemen & 0.00414 & Armenia & 0.0034 & Nicaragua & 0.00371 & Malta & 0.00039 \\
\hline Libya & 0.0189 & Iraq & 0.00332 & Estonia & 0.0019 & Bolivia & 0.00340 & Luxembourg & 0.00025 \\
\hline Uganda & 0.0184 & Vietnam & 0.00324 & Montenegro & 0.0005 & El Salvador & 0.00165 & Iceland & 0.00007 \\
\hline Burkina Faso & 0.0173 & Oman & 0.00323 & & & Bahamas & 0.00149 & Monaco & 0.00007 \\
\hline Malawi & 0.0172 & Kazakhstan & 0.00257 & & & Belize & 0.00070 & Andorra & 0.00005 \\
\hline Madagascar & 0.0170 & Fiji & 0.00203 & & & Suriname & 0.00061 & San Marino & 0.00004 \\
\hline Mauritania & 0.0163 & Cyprus & 0.00200 & & & Barbados & 0.00046 & Liechtenstein & 0.00003 \\
\hline Sudan & 0.0159 & Papua New Guinea & 0.00196 & & & Haiti & 0.00020 & & \\
\hline Togo & 0.0150 & Syrian Arab Republic & 0.00168 & & & Antigua and Barbuda & 0.00015 & & \\
\hline Gabon & 0.0147 & Bahrain & 0.00149 & & & Saint Lucia & 0.00013 & & \\
\hline Benin & 0.0136 & Uzbekistan & 0.00148 & & & Saint Kitts and Nevis & 0.00002 & & \\
\hline Namibia & 0.0124 & Brunei & 0.00092 & & & St Vincent \& Grenadines & 0.00002 & & \\
\hline Mauritius & 0.0121 & Lebanon & 0.00082 & & & Grenada & 0.00001 & & \\
\hline Cameroon & 0.0104 & DPR Korea & 0.00076 & & & Dominica & 0.00001 & & \\
\hline South Sudan & 0.0098 & Afghanistan & 0.00075 & & & & & & \\
\hline Botswana & 0.0097 & Cambodia & 0.00062 & & & & & & \\
\hline Sierra Leone & 0.0087 & Turkmenistan & 0.00060 & & & & & & \\
\hline Lesotho & 0.0087 & Mongolia & 0.00048 & & & & & & \\
\hline DR Congo & 0.0082 & Tajikistan & 0.00044 & & & & & & \\
\hline Eritrea & 0.0072 & Kyrgyzstan & 0.00042 & & & & & & \\
\hline Djibouti & 0.0071 & Laos & 0.00040 & & & & & & \\
\hline Gambia & 0.0062 & Bhutan & 0.00033 & & & & & & \\
\hline Central African Republic & 0.0061 & Maldives & 0.00022 & & & & & & \\
\hline Burundi & 0.0059 & Solomon Islands & 0.00022 & & & & & & \\
\hline Rwanda & 0.0055 & Timor Leste & 0.00018 & & & & & & \\
\hline Swaziland & 0.0050 & Tonga & 0.00008 & & & & & & \\
\hline Somalia & 0.0048 & Kiribati & 0.00007 & & & & & & \\
\hline Cape Verde & 0.0045 & Vanuatu & 0.00007 & & & & & & \\
\hline Comoros & 0.0030 & Samoa & 0.00005 & & & & & & \\
\hline Chad & 0.0029 & Micronesia & 0.00003 & & & & & & \\
\hline Guinea-Bissau & 0.0024 & Nauru & 0.00002 & & & & & & \\
\hline Liberia & 0.0023 & Marshall Islands & 0.00002 & & & & & & \\
\hline Sao Tome and Principe & 0.0019 & Tuvalu & 0.00002 & & & & & & \\
\hline Equatorial Guinea & 0.0012 & Palau & 0.00002 & & & & & & \\
\hline Seychelles & 0.0005 & & & & & & & & \\
\hline
\end{tabular}




\section{Appendix 3: Entitlements and relative deviations}

\begin{tabular}{|c|c|c|c|c|c|c|}
\hline \multirow[t]{2}{*}{ Country } & \multicolumn{2}{|c|}{$\mathbf{A E}$} & \multicolumn{2}{|c|}{$\mathbf{P E}$} & \multicolumn{2}{|c|}{ RE } \\
\hline & $\alpha_{i j}^{\mathrm{AE}}$ & $R_{i j}^{\mathrm{AE}}$ & $\beta_{i j}^{\mathrm{PE}}$ & $R_{i j}^{\mathrm{PE}}$ & $\beta_{j}^{\mathrm{RE}}$ & $R_{j}^{\mathrm{RE}}$ \\
\hline Africa & - & - & - & - & 0.259 & 0.573 \\
\hline Algeria & 0.0080 & 0.631 & 0.0080 & 1.301 & - & - \\
\hline Angola & 0.0059 & 0.861 & 0.0059 & 0.523 & - & - \\
\hline Benin & 0.0040 & 1.264 & 0.0040 & 0.556 & - & - \\
\hline Botswana & 0.0019 & 2.654 & 0.0019 & 0.811 & - & - \\
\hline Burkina Faso & 0.0054 & 0.927 & 0.0054 & 0.500 & - & - \\
\hline Burundi & 0.0039 & 1.299 & 0.0039 & 0.253 & - & - \\
\hline Cameroon & 0.0059 & 0.849 & 0.0059 & 0.283 & - & - \\
\hline Cape Verde & 0.0009 & 5.339 & 0.0009 & 0.789 & - & - \\
\hline Central African Republic & 0.0028 & 1.792 & 0.0028 & 0.361 & - & - \\
\hline Chad & 0.0045 & 1.122 & 0.0045 & 0.113 & - & - \\
\hline Comoros & 0.0012 & 4.387 & 0.0012 & 0.423 & - & - \\
\hline Congo & 0.0027 & 1.870 & 0.0027 & 1.256 & - & - \\
\hline Cote d'Ivoire & 0.0060 & 0.846 & 0.0060 & 0.574 & - & - \\
\hline Democratic Republic of the Congo & 0.0109 & 0.463 & 0.0109 & 0.129 & - & - \\
\hline Djibouti & 0.0013 & 3.989 & 0.0013 & 0.889 & - & - \\
\hline Egypt & 0.0121 & 0.418 & 0.0121 & 0.507 & - & - \\
\hline Equatorial Guinea & 0.0011 & 4.493 & 0.0011 & 0.171 & - & - \\
\hline Eritrea & 0.0031 & 1.641 & 0.0031 & 0.398 & - & - \\
\hline Ethiopia & 0.0122 & 0.413 & 0.0122 & 0.268 & - & - \\
\hline Gabon & 0.0016 & 3.065 & 0.0016 & 1.386 & - & - \\
\hline Gambia & 0.0018 & 2.860 & 0.0018 & 0.608 & - & - \\
\hline Ghana & 0.0066 & 0.761 & 0.0066 & 0.834 & - & - \\
\hline Guinea & 0.0042 & 1.190 & 0.0042 & 0.822 & - & - \\
\hline Guinea-Bissau & 0.0017 & 3.055 & 0.0017 & 0.230 & - & - \\
\hline Kenya & 0.0085 & 0.591 & 0.0085 & 0.550 & - & - \\
\hline Lesotho & 0.0020 & 2.552 & 0.0020 & 0.721 & - & - \\
\hline Liberia & 0.0027 & 1.882 & 0.0027 & 0.140 & - & - \\
\hline Libya & 0.0034 & 1.492 & 0.0034 & 0.878 & - & - \\
\hline Madagascar & 0.0061 & 0.826 & 0.0061 & 0.434 & - & - \\
\hline Malawi & 0.0052 & 0.974 & 0.0052 & 0.513 & - & - \\
\hline Mali & 0.0053 & 0.959 & 0.0053 & 0.707 & - & - \\
\hline Mauritania & 0.0025 & 2.022 & 0.0025 & 1.024 & - & - \\
\hline Mauritius & 0.0015 & 3.299 & 0.0015 & 1.286 & - & - \\
\hline Morocco & 0.0076 & 0.665 & 0.0076 & 0.895 & - & - \\
\hline Mozambique & 0.0065 & 0.778 & 0.0065 & 0.726 & - & - \\
\hline Namibia & 0.0020 & 2.489 & 0.0020 & 0.955 & - & - \\
\hline Niger & 0.0053 & 0.955 & 0.0053 & 0.653 & - & - \\
\hline Nigeria & 0.0169 & 0.299 & 0.0169 & 0.404 & - & - \\
\hline Rwanda & 0.0044 & 1.154 & 0.0044 & 0.203 & - & - \\
\hline Sao Tome and Principe & 0.0005 & 9.246 & 0.0005 & 0.610 & - & - \\
\hline
\end{tabular}




\begin{tabular}{|c|c|c|c|c|c|c|}
\hline Senegal & 0.0047 & 1.066 & 0.0047 & 0.972 & - & - \\
\hline Seychelles & 0.0004 & 12.784 & 0.0004 & 0.241 & - & - \\
\hline Sierra Leone & 0.0033 & 1.552 & 0.0033 & 0.442 & - & - \\
\hline Somalia & 0.0041 & 1.231 & 0.0041 & 0.193 & - & - \\
\hline South Africa & 0.0095 & 0.531 & 0.0095 & 0.517 & - & - \\
\hline South Sudan & 0.0042 & 1.192 & 0.0042 & 0.378 & - & - \\
\hline Sudan & 0.0078 & 0.649 & 0.0078 & 0.327 & - & - \\
\hline Swaziland & 0.0015 & 3.453 & 0.0015 & 0.604 & - & - \\
\hline Togo & 0.0033 & 1.532 & 0.0033 & 0.718 & - & - \\
\hline Tunisia & 0.0043 & 1.162 & 0.0043 & 1.254 & - & - \\
\hline Uganda & 0.0078 & 0.650 & 0.0078 & 0.359 & - & - \\
\hline United Republic of Tanzania & 0.0089 & 0.570 & 0.0089 & 0.612 & - & - \\
\hline Zambia & 0.0049 & 1.039 & 0.0049 & 0.957 & - & - \\
\hline Zimbabwe & 0.0048 & 1.061 & 0.0048 & 1.020 & - & - \\
\hline Asia & - & - & - & - & 0.362 & 0.552 \\
\hline Afghanistan & 0.0075 & 0.671 & 0.0075 & 0.016 & - & - \\
\hline Bahrain & 0.0015 & 3.348 & 0.0015 & 0.166 & - & - \\
\hline Bangladesh & 0.0164 & 0.308 & 0.0164 & 0.225 & - & - \\
\hline Bhutan & 0.0011 & 4.413 & 0.0011 & 0.050 & - & - \\
\hline Brunei & 0.0008 & 5.954 & 0.0008 & 0.196 & - & - \\
\hline Cambodia & 0.0050 & 1.000 & 0.0050 & 0.022 & - & - \\
\hline China & 0.0487 & 0.211 & 0.0487 & 2.072 & - & - \\
\hline Cyprus & 0.0012 & 4.180 & 0.0012 & 0.278 & - & - \\
\hline DPR Korea & 0.0066 & 0.762 & 0.0066 & 0.021 & - & - \\
\hline Fiji & 0.0012 & 4.053 & 0.0012 & 0.240 & - & - \\
\hline India & 0.0470 & 0.107 & 0.0470 & 0.547 & - & - \\
\hline Indonesia & 0.0208 & 0.243 & 0.0208 & 0.261 & - & - \\
\hline Iran & 0.0115 & 0.437 & 0.0115 & 0.095 & - & - \\
\hline Iraq & 0.0076 & 0.668 & 0.0076 & 0.071 & - & - \\
\hline Japan & 0.0151 & 0.334 & 0.0151 & 0.941 & - & - \\
\hline Jordan & 0.0033 & 1.512 & 0.0033 & 0.727 & - & - \\
\hline Kazakhstan & 0.0054 & 0.939 & 0.0054 & 0.072 & - & - \\
\hline Kiribati & 0.0004 & 11.918 & 0.0004 & 0.019 & - & - \\
\hline Kuwait & 0.0022 & 2.273 & 0.0022 & 0.434 & - & - \\
\hline Kyrgyzstan & 0.0031 & 1.628 & 0.0031 & 0.022 & - & - \\
\hline Laos & 0.0033 & 1.510 & 0.0033 & 0.020 & - & - \\
\hline Lebanon & 0.0028 & 1.829 & 0.0028 & 0.042 & - & - \\
\hline Malaysia & 0.0072 & 0.706 & 0.0072 & 0.938 & - & - \\
\hline Maldives & 0.0008 & 6.691 & 0.0008 & 0.054 & - & - \\
\hline Marshall Islands & 0.0003 & 16.176 & 0.0003 & 0.016 & - & - \\
\hline Micronesia (Federated States of) & 0.0004 & 11.284 & 0.0004 & 0.013 & - & - \\
\hline Mongolia & 0.0022 & 2.265 & 0.0022 & 0.043 & - & - \\
\hline Myanmar & 0.0093 & 0.543 & 0.0093 & 0.089 & - & - \\
\hline Nauru & 0.0001 & 37.133 & 0.0001 & 0.015 & - & - \\
\hline Nepal & 0.0073 & 0.687 & 0.0073 & 0.118 & - & - \\
\hline
\end{tabular}




\begin{tabular}{|c|c|c|c|c|c|c|}
\hline Oman & 0.0022 & 2.254 & 0.0022 & 0.232 & - & - \\
\hline Pakistan & 0.0177 & 0.285 & 0.0177 & 0.667 & - & - \\
\hline Palau & 0.0002 & 26.282 & 0.0002 & 0.026 & - & - \\
\hline Papua New Guinea & 0.0035 & 1.436 & 0.0035 & 0.089 & - & - \\
\hline Philippines & 0.0130 & 0.389 & 0.0130 & 0.178 & - & - \\
\hline Qatar & 0.0018 & 2.835 & 0.0018 & 0.397 & - & - \\
\hline Republic of Korea & 0.0093 & 0.542 & 0.0093 & 0.678 & - & - \\
\hline Samoa & 0.0006 & 8.788 & 0.0006 & 0.009 & - & - \\
\hline Saudi Arabia & 0.0070 & 0.718 & 0.0070 & 0.139 & - & - \\
\hline Singapore & 0.0030 & 1.667 & 0.0030 & 0.974 & - & - \\
\hline Solomon Islands & 0.0010 & 5.126 & 0.0010 & 0.046 & - & - \\
\hline Sri Lanka & 0.0061 & 0.823 & 0.0061 & 0.278 & - & - \\
\hline Syrian Arab Republic & 0.0061 & 0.832 & 0.0061 & 0.044 & - & - \\
\hline Tajikistan & 0.0035 & 1.434 & 0.0035 & 0.020 & - & - \\
\hline Thailand & 0.0112 & 0.452 & 0.0112 & 0.241 & - & - \\
\hline Timor Leste & 0.0014 & 3.546 & 0.0014 & 0.022 & - & - \\
\hline Tonga & 0.0004 & 11.657 & 0.0004 & 0.027 & - & - \\
\hline Turkmenistan & 0.0030 & 1.675 & 0.0030 & 0.029 & - & - \\
\hline Tuvalu & 0.0001 & 37.933 & 0.0001 & 0.022 & - & - \\
\hline United Arab Emirates & 0.0037 & 1.372 & 0.0037 & 0.576 & - & - \\
\hline Uzbekistan & 0.0070 & 0.718 & 0.0070 & 0.034 & - & - \\
\hline Vanuatu & 0.0007 & 7.681 & 0.0007 & 0.014 & - & - \\
\hline Vietnam & 0.0126 & 0.401 & 0.0126 & 0.042 & - & - \\
\hline Yemen & 0.0066 & 0.767 & 0.0066 & 0.101 & - & - \\
\hline$E E$ & - & - & - & - & 0.093 & 1.613 \\
\hline Albania & 0.0024 & 2.101 & 0.0024 & 0.160 & - & - \\
\hline Armenia & 0.0024 & 2.138 & 0.0024 & 0.086 & - & - \\
\hline Azerbaijan & 0.0041 & 1.241 & 0.0041 & 0.267 & - & - \\
\hline Belarus & 0.0042 & 1.214 & 0.0042 & 0.375 & - & - \\
\hline Bosnia and Herzegovina & 0.0026 & 1.939 & 0.0026 & 0.113 & - & - \\
\hline Bulgaria & 0.0037 & 1.374 & 0.0037 & 0.332 & - & - \\
\hline Croatia & 0.0028 & 1.792 & 0.0028 & 0.259 & - & - \\
\hline Czech Republic & 0.0043 & 1.161 & 0.0043 & 0.727 & - & - \\
\hline Estonia & 0.0016 & 3.247 & 0.0016 & 0.080 & - & - \\
\hline Georgia & 0.0028 & 1.802 & 0.0028 & 0.173 & - & - \\
\hline Hungary & 0.0042 & 1.190 & 0.0042 & 0.821 & - & - \\
\hline Latvia & 0.0020 & 2.506 & 0.0020 & 0.110 & - & - \\
\hline Lithuania & 0.0024 & 2.063 & 0.0024 & 0.152 & - & - \\
\hline Montenegro & 0.0011 & 4.732 & 0.0011 & 0.032 & - & - \\
\hline Poland & 0.0083 & 0.608 & 0.0083 & 1.767 & - & - \\
\hline Republic of Moldova & 0.0025 & 1.989 & 0.0025 & 0.198 & - & - \\
\hline Romania & 0.0062 & 0.811 & 0.0062 & 1.034 & - & - \\
\hline Russian Federation & 0.0160 & 0.641 & 0.0160 & 6.292 & - & - \\
\hline Serbia & 0.0036 & 1.386 & 0.0036 & 0.380 & - & - \\
\hline Slovakia & 0.0031 & 1.609 & 0.0031 & 0.289 & - & - \\
\hline
\end{tabular}




\begin{tabular}{|c|c|c|c|c|c|c|}
\hline Slovenia & 0.0019 & 2.639 & 0.0019 & 0.169 & - & - \\
\hline TFYR Macedonia & 0.0019 & 2.620 & 0.0019 & 0.108 & - & - \\
\hline Ukraine & 0.0090 & 0.558 & 0.0090 & 1.299 & - & - \\
\hline GRULAC & - & - & - & - & 0.130 & 0.760 \\
\hline Antigua and Barbuda & 0.0004 & 12.625 & 0.0004 & 0.047 & - & - \\
\hline Argentina & 0.0085 & 0.592 & 0.0085 & 1.174 & - & - \\
\hline Bahamas & 0.0008 & 6.422 & 0.0008 & 0.318 & - & - \\
\hline Barbados & 0.0007 & 7.193 & 0.0007 & 0.119 & - & - \\
\hline Belize & 0.0007 & 6.736 & 0.0007 & 0.130 & - & - \\
\hline Bolivia & 0.0042 & 1.193 & 0.0042 & 0.126 & - & - \\
\hline Brazil & 0.0187 & 0.269 & 0.0187 & 1.237 & - & - \\
\hline Chile & 0.0056 & 0.909 & 0.0056 & 1.064 & - & - \\
\hline Colombia & 0.0091 & 0.553 & 0.0091 & 0.695 & - & - \\
\hline Costa Rica & 0.0029 & 1.742 & 0.0029 & 0.301 & - & - \\
\hline Cuba & 0.0045 & 1.121 & 0.0045 & 0.335 & - & - \\
\hline Dominica & 0.0003 & 14.446 & 0.0003 & 0.006 & - & - \\
\hline Dominican Republic & 0.0042 & 1.193 & 0.0042 & 0.281 & - & - \\
\hline Ecuador & 0.0051 & 0.989 & 0.0051 & 0.508 & - & - \\
\hline El Salvador & 0.0033 & 1.511 & 0.0033 & 0.077 & - & - \\
\hline Grenada & 0.0004 & 11.633 & 0.0004 & 0.007 & - & - \\
\hline Guatemala & 0.0051 & 0.991 & 0.0051 & 0.165 & - & - \\
\hline Guyana & 0.0012 & 4.329 & 0.0012 & 0.562 & - & - \\
\hline Haiti & 0.0042 & 1.190 & 0.0042 & 0.006 & - & - \\
\hline Honduras & 0.0037 & 1.364 & 0.0037 & 0.284 & - & - \\
\hline Jamaica & 0.0022 & 2.271 & 0.0022 & 0.260 & - & - \\
\hline Mexico & 0.0143 & 0.353 & 0.0143 & 1.273 & - & - \\
\hline Nicaragua & 0.0032 & 1.563 & 0.0032 & 0.165 & - & - \\
\hline Panama & 0.0025 & 2.005 & 0.0025 & 0.292 & - & - \\
\hline Paraguay & 0.0034 & 1.480 & 0.0034 & 0.176 & - & - \\
\hline Peru & 0.0072 & 0.697 & 0.0072 & 0.503 & - & - \\
\hline Saint Kitts and Nevis & 0.0003 & 16.427 & 0.0003 & 0.006 & - & - \\
\hline Saint Lucia & 0.0006 & 9.008 & 0.0006 & 0.034 & - & - \\
\hline Saint Vincent and the Grenadines & 0.0004 & 11.372 & 0.0004 & 0.011 & - & - \\
\hline Suriname & 0.0010 & 5.192 & 0.0010 & 0.099 & - & - \\
\hline Trinidad and Tobago & 0.0016 & 3.247 & 0.0016 & 0.419 & - & - \\
\hline Uruguay & 0.0025 & 2.049 & 0.0025 & 0.813 & - & - \\
\hline Venezuela & 0.0072 & 0.699 & 0.0072 & 2.294 & - & - \\
\hline WEOG & - & - & - & - & 0.155 & 2.592 \\
\hline Andorra & 0.0004 & 12.908 & 0.0004 & 0.020 & - & - \\
\hline Australia & 0.0063 & 0.797 & 0.0063 & 0.254 & - & - \\
\hline Austria & 0.0039 & 1.298 & 0.0039 & 2.033 & - & - \\
\hline Belgium & 0.0044 & 1.149 & 0.0044 & 0.638 & - & - \\
\hline Canada & 0.0078 & 0.645 & 0.0078 & 0.570 & - & - \\
\hline Denmark & 0.0032 & 1.596 & 0.0032 & 0.920 & - & - \\
\hline
\end{tabular}




\begin{tabular}{lrrrrrr}
\hline Finland & 0.0031 & 1.624 & 0.0031 & 0.750 & - & - \\
France & 0.0108 & 0.953 & 0.0108 & 9.351 & - & - \\
Germany & 0.0122 & 0.415 & 0.0122 & 1.652 & - & - \\
Greece & 0.0045 & 1.116 & 0.0045 & 0.149 & - & - \\
Iceland & 0.0008 & 6.646 & 0.0008 & 0.008 & - & - \\
Ireland & 0.0028 & 1.779 & 0.0028 & 1.088 & - & - \\
Israel & 0.0037 & 1.381 & 0.0037 & 0.022 & - & - \\
Italy & 0.0104 & 0.483 & 0.0104 & 1.101 & - & - \\
Liechtenstein & 0.0003 & 19.810 & 0.0003 & 0.008 & - & - \\
Luxembourg & 0.0010 & 5.279 & 0.0010 & 0.032 & - & - \\
Malta & 0.0009 & 5.827 & 0.0009 & 0.059 & - & - \\
Monaco & 0.0003 & 19.984 & 0.0003 & 0.051 & - & - \\
Netherlands & 0.0055 & 0.923 & 0.0055 & 1.001 & - & - \\
New Zealand & 0.0028 & 1.799 & 0.0028 & 0.472 & - & - \\
Norway & 0.0030 & 1.702 & 0.0030 & 0.720 & - & - \\
Portugal & 0.0044 & 1.151 & 0.0044 & 0.508 & - & - \\
San Marino & 0.0002 & 21.176 & 0.0002 & 0.021 & - & - \\
Spain & 0.0091 & 0.554 & 0.0091 & 0.921 & - & - \\
Sweden & 0.0041 & 1.228 & 0.0041 & 0.926 & - & - \\
Switzerland & 0.0037 & 1.358 & 0.0037 & 0.878 & - & - \\
Turkey & 0.0114 & 0.441 & 0.0114 & 1.299 & - & - \\
United Kingdom & 0.0106 & 0.973 & 0.0106 & 9.552 & - & - \\
United States of America & 0.0236 & 0.435 & 0.0236 & 4.270 & - & - \\
\hline
\end{tabular}

